\title{
Genetic Factors Associated With Tardive Dyskinesia: From Pre-clinical Models to Clinical Studies
}

\author{
Evangelia Eirini Tsermpini, Sara Redenšek and Vita Dolžan *
}

Pharmacogenetics Laboratory, Institute of Biochemistry and Molecular Genetics, Faculty of Medicine, University of Ljubljana, Ljubljana, Slovenia

Tardive dyskinesia is a severe motor adverse event of antipsychotic medication, characterized by involuntary athetoid movements of the trunk, limbs, and/or orofacial areas. It affects two to ten patients under long-term administration of antipsychotics that do not subside for years even after the drug is stopped. Dopamine, serotonin, cannabinoid receptors, oxidative stress, plasticity factors, signaling cascades, as well as CYP isoenzymes and transporters have been associated with tardive dyskinesia (TD) occurrence in terms of genetic variability and metabolic capacity. Besides the factors related to the drug and the dose and patients' clinical characteristics, a very crucial variable

OPEN ACCESS

Edited by:

Alessio Squassina,

University of Cagliari, Italy

Reviewed by:

Clement Zai,

Centre for Addiction and Mental Health (CAMH), Canada

Claudia Pisanu,

University of Cagliari, Italy

*Correspondence:

Vita Dolžan

vita.dolzan@mf.uni-lj.si

Specialty section: This article was submitted to

Pharmacogenetics and

Pharmacogenomics,

a section of the journal

Frontiers in Pharmacology

Received: 13 December 2021

Accepted: 31 December 2021

Published: 24 January 2022

Citation:

Tsermpini EE, Redenšek S and

Dolžan V (2022) Genetic Factors

Associated With Tardive Dyskinesia:

From Pre-clinical Models to

Clinical Studies.

Front. Pharmacol. 12:834129.

doi: 10.3389/fphar.2021.834129 of TD development is individual susceptibility and genetic predisposition. This review summarizes the studies in experimental animal models and clinical studies focusing on the impact of genetic variations on TD occurrence. We identified eight genes emerging from preclinical findings that also reached statistical significance in at least one clinical study. The results of clinical studies are often conflicting and non-conclusive enough to support implementation in clinical practice.

Keywords: tardive dyskinesia, antipsychotics, animal models, pharmacogenetics, GWAS

\section{INTRODUCTION}

Psychiatric disorders affect approximately 30\% of the population worldwide (James et al., 2018). They can be treated with a combination of different drugs, such as antipsychotics, antidepressants, mood stabilizers, and anxiolytic drugs. According to the National Health and Nutrition Examination Survey (NHANES) data collected between 2013 and 2018, which included 17,691 U.S. residents, the estimated prevalence of antipsychotic drug use was 1.6\% (Dennis et al., 2020). In 2020, antipsychotic drugs were prescribed more than 5 million times (Dennis et al., 2020). The treatment of psychiatric disorders is a challenge, and the drug efficacy is limited. Moreover, the administration of these drugs is usually accompanied by the occurrence of mild to serious adverse events (Reynolds 2007). Despite large number of typical and atypical antipsychotic drugs, it is difficult to find the safest drug with the maximum therapeutic efficacy for the patient. Additionally, patients treated with antipsychotics were at higher risk for comorbidities (Dennis et al., 2020). This can lead to polypharmacy and high risk of unpleasant adverse events (Ravyn et al., 2013).

Tardive dyskinesia (TD) is a severe motor adverse event of antipsychotic medication, characterized by involuntary athetoid movements of the trunk, limbs, and/or orofacial areas that affects $25.3 \%$ of patients under long-term treatment with antipsychotics. (Owens 2019; Islam et al., 2021). According to the Diagnostic and Statistical Manual of Mental Disorders, Fifth Edition (DSM$\mathrm{V})$, tardive dyskinesia is a drug-induced movement disorder that lasts for 1 month (American 
Psychiatric Association 2013). It is also a very persistent disorder, meaning that its symptoms do not subside for years even after the drug is stopped (Vasan and Padhy 2021) It decreases patients' quality of life and leads to difficulties in daily life and stigmatization (Owens 2019). TD severity is assessed with the Abnormal Involuntary Movement Scale (AIMS). This 12-item scale can serve as an essential tool for TD diagnosis in clinical practice when used by trained physicians and healthcare professionals. The first items refer to movements of different body regions, such as facial and oral areas, extremities, and trunk. The rest reflect the global judgment regarding movement severity and accounts for dental status (Guy 1976; Caroff et al., 2020). According to Schooler and Kane criteria, the prerequisites for TD diagnosis include at least 3 months of exposure to an antipsychotic drug, moderate abnormal movements in one body part or mild in two or more, and no other potential cause (Schooler and Kane 1982).

The development of TD is related to demographic variables, such as age, sex, and race, as well as the class of antipsychotics prescribed, the duration, and the dosage of the antipsychotic treatment (Zai et al., 2018b). Women, elderly patients, African Americans, patients with mood disorders, intellectual disability, or central nervous system injury, as well as patients with a past or current history of akathisia, parkinsonism, or acute dystonic reactions, are more susceptible to developing TD (Owens 2019; Keepers et al., 2020; Vasan and Padhy 2021). TD is caused mainly by the long-term exposure to antipsychotics, either first-generation (FGAs) or second-generation (SGAs) (Lee and Kang 2011; Zai et al., 2018b; Owens 2019). However, $20 \%$ of patients treated with FGAs experience TD. One of the underlying causes is the increased dopamine D2 affinity that characterizes FGAs (Vasan and Padhy 2021). On the contrary, the lower D2 affinity of SGAs, such as clozapine or quetiapine, might improve TD symptoms (Ricciardi et al., 2019; Vasan and Padhy 2021). Notably, a 12-years cross-national study that inspected the patterns of antipsychotic prescription in Taiwan, Hong Kong, Japan, and the United States, indicated that SGAs were more frequently prescribed in younger patients in all studied countries. Quetiapine and haloperidol were the most common in the United States and Hong Kong (Su et al., 2020). It is crucial to mention that among patients receiving an antipsychotic, only 1 out of 10 had a schizophrenia spectrum disorder diagnosis, while the rest had bipolar disorder, treatment-resistant depression, anxiety, personality disorders, autism, and/or other conditions (Loughlin et al., 2019; Dennis et al., 2020).

Although the results of two randomized controlled trials (RCTs) indicated that there was no association between the class of antipsychotics and TD frequency (Miller et al., 2008; Peluso et al., 2012), a meta-analysis published in 2018, which assessed 57 RCTs, suggested that the administration of SGAs is associated with lower risk for TD development (Carbon et al., 2018). Switching from FGAs to SGAs was proposed as a more efficient strategy for improvement of symptoms than treatment discontinuation (Bai et al., 2003) and a later systematic review confirmed a reduction of TD symptoms (Ricciardi et al., 2019). However, the 18-years long prospective study indicated that adding a SGA to existing FGA treatment was not necessarily associated with reduction in TD severity (Mentzel et al., 2017). The results are conflicting regarding the impact of duration and the dosage of the antipsychotic therapy on TD risk. A retrospective study suggested that the dose of antipsychotics was associated with high TD risk in patients with schizophrenia (Patterson-Lomba et al., 2019). In contrast, a meta-analysis of 26 studies (Takeuchi et al., 2020) and a review of 13 RCTs (Bergman et al., 2018) did not confirm this association.

The Curaçao Extrapyramidal Syndromes Study XII, a prospective study that lasted for 18 years and included 223 patients, suggested that an increase in the dose of antipsychotics can reduce the severity of TD (Mentzel et al., 2017). This finding is in line with other older studies with a small sample size (Kazamatsuri et al., 1972, Kazamatsuri et al., 1973; Gerlach et al., 1974; Korsgaard et al., 1984; Tamminga et al., 1994). However, attention should be paid to the potential masking effect of the increased dose on TD symptoms, and it should be emphasized that the alleviation is only short-term and that TD symptoms inevitably return after some time (Mentzel et al., 2017; Yoshida and Takeuchi 2021).

Age, sex, health behaviors, liver and renal function, comorbidities, and the administration of co-medication are important factors in choosing the right type of the antipsychotic drug and its dose (Ohmori et al., 2003; Ravyn et al., 2013). Apart from the above factors a very crucial variable of TD development is individual susceptibility and genetic predisposition to TD development. Dopamine, serotonin, cannabinoid receptors, oxidative stress, plasticity factors, signaling cascades, as well as CYP isoenzymes and transporters have been associated with TD occurrence, in terms of genetic variability, and metabolic capacity. The genetic variability of pharmacokinetic and pharmacodynamic genes can lead to decreased or increased drug plasma levels and impact the drug response, in terms of efficacy and toxicity (Ravyn et al., 2013).

To elucidate potential genetic factors contributing to the molecular pathogenesis of TD, this review first collected all the available data on preclinical animal studies of TD development induced by antipsychotic treatment published in the last 10 years. To achieve our aim, we performed a literature review of studies published until today found in the MEDLINE database, using combinations of the following keywords: "pharmacogenomics," "pharmacogenetics," "tardive dyskinesia," "drug-induced tardive dyskinesia," "antipsychotics," "adverse drug reactions," "genes," "genetic variations," "polymorphisms," and limited the search filter "species" to "humans." The respective search for preclinical animal studies was performed by using the search term "tardive dyskinesia" and limiting the search filter "species" to "other animals." Additional references were also identified and retrieved from the articles that emerged from the search using the above combinations. Next, we reviewed candidate gene and genome-wide association studies that focused on genetic variations in genes involved in pharmacokinetics and pharmacodynamics and drug-induced TD. The findings of larger, genome-wide association studies (GWAS) were also 
included. We elaborated on how this information can be used for patients' benefit.

\section{PRECLINICAL STUDIES OF TARDIVE DYSKINESIA DEVELOPMENT}

Candidate genes that would be relevant to be studied in regards to TD development could be derived from preclinical studies conducted primarily on experimental animals, such as mice, rats, and monkeys (Blanchet et al., 2012). In most models, TD is induced by treatment with the FGA haloperidol, commonly prescribed in patients with schizophrenia (Marder and Cannon 2019). Additionally, fluphenazine, one of the oldest antipsychotics (Matar et al., 2018) and reserpine, an indole alkaloid used as antipsychotic and antihypertensive agent (Soung et al., 2018) are used to induce TD in experimental animals as well. The phenotype of TD in animals is different in comparison to human beings since it presents with robust, seemingly purposeless chewing activity (so-called vacuous chewing movements or VCM), often fluctuating, and occurring in short bursts, occasionally associated with bruxism and tongue protrusions. VCM in animals usually occur shortly after treatment initiation or even after acute treatments, whereas in humans the development of TD takes longer (Blanchet et al., 2012). Many studies have been conducted in experimental animals to elucidate the underlying pathology of TD and determine potential pharmacotherapy. However, no consensus has been made so far.

We identified 43 animal studies dealing with TD pathogenesis and possible ways of treatment in the past 10 years. All of the studies are presented in the Supplementary Table S1. Animal experiments studied candidate pathways involved in TD development on the level of functional perturbations due to treatment with antipsychotics. Inflammation (Bishnoi and Boparai 2012; Grover et al., 2013; Thakur et al., 2015; Datta et al., 2016; Peroza et al., 2016; Sonego et al., 2018; Soung et al., 2018; Wang et al., 2021a) and oxidative stress defense (Patil et al., 2012; Grover et al., 2013; Nade et al., 2013; Thakur et al., 2015; Wang et al., 2015; Datta et al., 2016; Schaffer et al., 2016; Samad and Haleem 2017; Dhingra et al., 2018; Sonego et al., 2018; Soung et al., 2018; Tsai et al., 2019; Wang et al., 2021a) pathways were among the most studied ones. Accordingly, different antioxidants were tested as potential agents for the treatment of TD. Many studies showed decreased levels of catalase (CAT), superoxide dismutase (SOD), and glutathione (GSH), either in their quantity or antioxidant capacity, upon treatment with haloperidol (Grover et al., 2013; Thakur et al., 2015; Datta et al., 2016; Samad and Haleem 2017; Dhingra et al., 2018; Sonego et al., 2018; Tsai et al., 2019; Wang et al., 2021a), reserpine (Patil et al., 2012; Nade et al., 2013; Wang et al., 2015; Soung et al., 2018) or fluphenazine (Schaffer et al., 2016). Studies have also shown that a plethora of cytokines are elevated upon treatment with antipsychotics, such as TNF- $\alpha$ (Bishnoi and Boparai 2012; Grover et al., 2013; Thakur et al., 2015; Datta et al., 2016; Peroza et al., 2016; Sonego et al., 2018; Soung et al., 2018; Wang et al., 2021a), IL-1 $\beta$ (Grover et al., 2013; Thakur et al., 2015; Datta et al., 2016; Peroza et al., 2016; Sonego et al., 2018; Wang et al., 2021a), IL6 (Datta et al., 2016; Peroza et al., 2016; Sonego et al., 2018;
Soung et al., 2018; Wang et al., 2021a), and IFN- $\gamma$ (Peroza et al., 2016). On the contrary, IL-10 is decreased, due to its role as an antiinflammatory cytokine (Peroza et al., 2016; Sonego et al., 2018). Consequently, some agents with antioxidative and antiinflammatory properties were tested as potential drugs for TD, such as resveratrol (Busanello et al., 2012, Busanello et al., 2017), vitamin E (An et al., 2016; Shi et al., 2016), lycopene (Datta et al., 2016), L-theanine (Chen et al., 2018; Soung et al., 2018; Tsai et al., 2019), cannabidiol (Sonego et al., 2018; Kajero et al., 2020), and catechin (Wang et al., 2015; Reinheimer et al., 2020). Additionally, several different plant-based compounds were tested (Patil et al., 2012; Sekiguchi et al., 2012; An et al., 2013; An et al., 2016; Shi et al., 2016; Samad and Haleem 2017; Dhingra et al., 2018; Wang et al., 2021a). A widely measured endpoint upon TD induction is the severity of apoptosis in different brain areas. Caspase-3 was elevated in animals with TD (Bishnoi and Boparai 2012; Soung et al., 2018; Wang et al., 2021a). Furthermore, the transcription level of the proapoptotic $B A X$ was elevated, whereas antiapoptotic $B A D$ mRNA was decreased (An et al., 2016). In light of this brain-derived neurotrophic factor (BDNF), a molecule involved in the viability of neurons, was shown to be decreased in several brain regions of rats with haloperidol-induced VCM. It was rescued with antioxidantacting Ginkgo biloba extract and vitamin E (Shi et al., 2016).

Since TD arises from perturbations in neurotransmitter systems, a lot of emphasis was put on that in terms of endpoint measurements when TD was induced in experimental animals. Several different neurotransmitter systems were studied, such as dopaminergic, serotonergic, cholinergic, and glutamatergic. As expected, the most widely studied pathway is the dopaminergic pathway. The binding capacities or expression levels of different components of dopaminergic pathways were assessed upon haloperidol treatment. It was shown that the function or activity of dopamine transporter (Bordia et al., 2012; Lévesque et al., 2017), monoamine oxidase B (MAO-B) (Busanello et al., 2017), and dopamine receptor 1 (DRD1) (Mahmoudi et al., 2014) were decreased, whereas binding capacities or activities of the tyrosine hydroxylase (TH) (Lévesque et al., 2017; Ceretta et al., 2018) and dopamine receptor 3 (DRD3) (Mahmoudi et al., 2014; Hernandez et al., 2019) were increased. The storage capacity of the monoamine neurotransmitters was decreased since the expression of vesicular monoamine transporter 2 (VMAT2) was shown to be reduced upon TD induction (Lévesque et al., 2017). The serotonergic system works hand in hand with the dopaminergic system also in the context of TD development (Crisafulli et al., 2013) (34). The serotonin receptor 2A (HTR2A) mRNA was decreased upon chronic exposure to haloperidol in monkeys (Lévesque et al., 2017). All of the above indicate a lack of adaptation of the aminergic neurotransmission in TD development (Lévesque et al., 2017; Hauser and Truong 2018). Not only were those components of serotonergic and dopaminergic systems dysregulated, but the concentrations of neurotransmitters themselves were decreased (Dhingra et al., 2018; Soung et al., 2018; Wang et al., 2021a).

Studies of TD in animal models showed that other neurotransmitter systems, such as acetylcholine and glutamate, 
are also affected. Neuronal acetylcholine receptor subunits, for instance alpha-4 (CHRNA4), beta-2 (CHRNB2), and alpha-6 (CHRNA6), were decreased upon haloperidol treatment (Bordia et al., 2012). Additionally, the acetylcholinesterase activity was decreased in different brain areas in haloperidol-induced orofacial dyskinesia in rats, recuperated by the vitamin B cocktail (de Oliveira et al., 2013). On the other hand, glutamate receptor subunits, GRIN2A and GRIN2B were increased in the putamen of haloperidol treated monkeys (Lévesque et al., 2017). Along with that, glutamate transporter (SLC1A2) was decreased in the striatum and cortex of haloperidol-treated rats (Sekiguchi et al., 2012). Furthermore, cannabinoid receptor type 1 (CNR1) was shown to be increased in haloperidol-induced orofacial dyskinesia in rats (Röpke et al., 2021).

A few animal studies explored the genetic background of TD as well. Crowley et al. conducted a genome-wide association study in 27 inbred strains of mice treated with haloperidol for 60 days. TD was recorded in case the animal developed VCM. The association mapping analysis highlighted six genes with variants associated with the development of VCM, namely CPEB2, BST1, PIT2, ZIC4, PLSCR1, and DRD1A, of which the latter was concluded to be the most important one (Crowley et al., 2012).

TD was also induced in knock-out animals to dissect the role of individual genes in the development of TD. Khan et al. induced TD in the GNAL knock-out and wild-type mice with haloperidol. GNAL encodes G $\alpha$ (olf), the $\alpha$ subunit of a heterotrimeric GTPbinding protein that couples to downstream signaling partners. $\mathrm{G} \alpha$ (olf) is highly enriched in the striatum, where it positively couples with DRD1 and ADORA2A to activate adenylyl cyclase, thereby increasing intracellular cAMP levels in DRD1-expressing striatonigral and DRD2-expressing striatopallidal neurons, respectively. $\mathrm{G} \alpha$ (olf) levels serve as a determinant of cAMP signal-dependent activity. GNAL \pm mice presented higher levels of DNA damage and cell death in the brain. This was accompanied by reduced levels of cAMP and histone $\mathrm{H} 3$ phosphorylation in the striatum and enhanced behavioral abnormalities after haloperidol treatment in comparison to $G_{N A L^{+/+}}$haloperidol treated mice (Khan et al., 2019). Results of this study warrant further functional research on the role of $\mathrm{G} \alpha$ (olf) in TD.

Animal studies focusing on a particular protein function in TD development have been published as well. A study conducted by Nagaoka et al. studied the role of striatal transient receptor potential vanilloid 1 (TRPV1) in acetaminophen treatment of orofacial dyskinesia induced by haloperidol in rats. First, they successfully showed that acetaminophen and the acetaminophen metabolite AM404 are valid options for alleviation of TD. They also showed that TRPV1 is a crucial component in the mechanism of acetaminophen action since the anti-dyskinetic effect was lost in the TRPV1 knock-out animals if compared to wild-type rats (Nagaoka et al., 2021). Furthermore, in a monkey model of TD induced by haloperidol, monkeys treated with haloperidol without TD had a higher expression of the transcription factor NUR77. This indicates that NUR77, which is involved in a neuroadaptive response mounted against abnormal motor behaviors following typical antipsychotic drug exposure, is associated with a decreased risk for TD development (Mahmoudi et al., 2013). S100B, a calcium-binding protein, exerts neuroprotective and neurodegenerative effects depending on its concentration. Low concentrations appear to have neuroprotective effects on neuronal growth and survival. On the other hand, higher concentrations induce neurodegeneration and apoptosis. A rat model of TD showed increased levels of S100B, which were rescued by antioxidant administration (An et al., 2016). A study conducted by Miksys et al. dealt with brain metabolism levels of haloperidol and their association with TD development in a rat model. They show that lower CYP2D6 activity in the brain decreases the risk for catalepsy and VCM development, whereas high CYP2D6 activity increases VCM and catalepsy development (Miksys et al., 2017).

Preclinical studies showed many insights into the pathogenesis of TD and, more importantly, many suggested how this troublesome adverse event of antipsychotic treatment could be tackled. However, there are some caveats to the animal models of TD. The phenotype of TD in animals differs from the one in human beings, since TD in animals presents mostly as VCM focused on the orofacial area whereas in humans it affects other body parts as well. Additionally, VCM are often observed after $>2-3$ weeks of subchronic haloperidol treatment, which is a relatively long time in the average life span of a rat (Kulkarni and Dhir 2011). The percentage of animals developing VCM due to antipsychotic treatment is much higher than the percentage in patients as well (Blanchet et al., 2012). All of the above indicates that animal studies cannot substitute the findings from studies in human beings. However, they present an invaluable basis for the direction of human studies towards a better understanding and management of TD.

\section{PHARMACOGENOMIC STUDIES FOCUSING ON THE ASSOCIATION BETWEEN TARDIVE DYSKINESIA AND GENES INVOLVED IN THE PHARMACOKINETICS OF ANTIPSYCHOTICS}

Pharmacogenetics aims to provide the appropriate drug for the individual patient in terms of efficacy and adverse events' occurrence based on the patient's genetic background (Ravyn et al., 2013). For many years the main focus of the research was genetic variability of drug metabolizing enzymes, mainly cytochromes P450 (Ohmori et al., 2003; Gopisankar 2017). The metabolizing properties and capacities of cytochromes vary a lot and they can metabolize diverse substrates (Ravyn et al., 2013; Gopisankar 2017).

The most important as well as highly polymorphic drugmetabolizing enzyme is CYP2D6. Interestingly, $30 \%$ of the drugs are primarily or partially metabolized by CYP2D6. Psychiatric drugs, including antipsychotics are among them 
TABLE 1 | Pharmacokinetics gene polymorphisms and associations with TD.

\begin{tabular}{|c|c|c|c|}
\hline Gene & $\begin{array}{l}\text { Genetic } \\
\text { polymorphisms }\end{array}$ & Association & References \\
\hline \multirow[t]{34}{*}{ CYP2D6 } & CYP2D6*2 & No & Ohmori et al. (1999); Inada et al. (2003); de Leon et al. (2005); Plesnicar et al. (2006); Grossman et al. (2008) \\
\hline & CYP2D6*3 & Yes & Kapitany et al. (1998); Jaanson et al. (2002); Ellingrod et al. (2002) \\
\hline & & No & $\begin{array}{l}\text { Arthur et al. (1995); Armstrong et al. (1997); Andreassen et al. (1997); Ohmori et al. (1998); Scordo et al. (2000); } \\
\text { Lohmann et al. (2003); Inada et al. (2003); de Leon et al. (2005); Plesnicar et al. (2006); Grossman et al. (2008); } \\
\text { Ivanova et al. (2016a) }\end{array}$ \\
\hline & CYP2D6*4 & Yes & Kapitany et al. (1998); Jaanson et al. (2002); Ellingrod et al. (2002); Ivanova et al. (2016a) \\
\hline & & No & $\begin{array}{l}\text { Arthur et al. (1995); Armstrong et al. (1997); Andreassen et al. (1997); Ohmori et al. (1998); Scordo et al. (2000); } \\
\text { Lohmann et al. (2003); Inada et al. (2003); Tiwari et al. (2005b); de Leon et al. (2005); Plesnicar et al. (2006); } \\
\text { Grossman et al. (2008) }\end{array}$ \\
\hline & CYP2D6*5 & Yes & Kapitany et al. (1998) \\
\hline & & No & $\begin{array}{l}\text { Arthur et al. (1995); Armstrong et al. (1997); Andreassen et al. (1997); Scordo et al. (2000); Lohmann et al. (2003); } \\
\text { de Leon et al. (2005); Plesnicar et al. (2006); Grossman et al. (2008) }\end{array}$ \\
\hline & CYP2D6*6 & No & $\begin{array}{l}\text { Andreassen et al. (1997); Scordo et al. (2000); Lohmann et al. (2003); de Leon et al. (2005); Plesnicar et al. (2006); } \\
\text { Grossman et al. (2008) }\end{array}$ \\
\hline & CYP2D6*7 & No & Andreassen et al. (1997); de Leon et al. (2005) \\
\hline & CYP2D6*8 & No & de Leon et al. (2005); Plesnicar et al. (2006) \\
\hline & CYP2D6*9 & No & de Leon et al. (2005); Plesnicar et al. (2006); Grossman et al. (2008) \\
\hline & CYP2D6*10 & Yes & Ohmori et al. (1998); Lam et al. (2001); Fu et al. (2006) \\
\hline & & No & Inada et al. (2003); Liou et al. (2004); de Leon et al. (2005); Plesnicar et al. (2006); Grossman et al. (2008) \\
\hline & CYP2D6*11 & No & de Leon et al. (2005); Plesnicar et al. (2006) \\
\hline & CYP2D6*12 & No & Inada et al. (2003); Plesnicar et al. (2006) \\
\hline & CYP2D6*14 & No & de Leon et al. (2005); Plesnicar et al. (2006) \\
\hline & CYP2D6*15 & No & Brockmöller et al. (2002); de Leon et al. (2005); Plesnicar et al. (2006) \\
\hline & CYP2D6*17 & No & Brockmöller et al. (2002); de Leon et al. (2005); Grossman et al. (2008) \\
\hline & CYP2D6*18 & No & de Leon et al. (2005) \\
\hline & CYP2D6*19 & No & de Leon et al. (2005) \\
\hline & CYP2D6*20 & No & de Leon et al. (2005) \\
\hline & CYP2D6*25 & No & de Leon et al. (2005) \\
\hline & CYP2D6*26 & No & de Leon et al. (2005) \\
\hline & CYP2D6*29 & No & de Leon et al. (2005); Grossman et al. (2008) \\
\hline & CYP2D6*30 & No & de Leon et al. (2005) \\
\hline & CYP2D6*31 & No & de Leon et al. (2005) \\
\hline & CYP2D6*35 & No & de Leon et al. (2005) \\
\hline & CYP2D6*36 & No & de Leon et al. (2005) \\
\hline & CYP2D6*37 & No & de Leon et al. (2005) \\
\hline & CYP2D6*40 & No & de Leon et al. (2005) \\
\hline & CYP2D6*41 & No & de Leon et al. (2005); Grossman et al. (2008) \\
\hline & CYP2D6*43 & No & de Leon et al. (2005) \\
\hline & CYP2D6*45 & No & de Leon et al. (2005) \\
\hline & CYP2D6 duplications & No & Scordo et al. (2000); de Leon et al. (2005); Plesnicar et al. (2006) \\
\hline \multirow[t]{4}{*}{ CYP1A2 } & CYP1A2*1F & Yes & Basile et al. (2000); Fu et al. (2006); Ivanova et al. (2015); Ivanova et al. (2016a) \\
\hline & & No & Schulze et al. (2001); Chong et al. (2003b); Matsumoto et al. (2004a); Grossman et al. (2008) \\
\hline & CYP1A2*1C & Yes & Tiwari et al. (2005a) \\
\hline & & No & Matsumoto et al. (2004a) \\
\hline CYP17A1 & rs743572 & Yes & Segman et al. (2002a); Ivanova et al. (2014) \\
\hline CYP3А4 & CYP3A4*1B & No & Tiwari et al. (2005b) \\
\hline \multirow[t]{3}{*}{$A B C B 1$} & rs1045642 & No & de Leon et al. (2005); De Luca et al. (2009) \\
\hline & rs1922242 & No & De Luca et al. (2009) \\
\hline & rs1045642, rs1922242 & Yes-haplotype & De Luca et al. (2009) \\
\hline
\end{tabular}

(Petrović et al., 2020). Depending on the genotype, the metabolizing phenotype differs, and the drug metabolism consequently changes. More specifically, based on their metabolizing capacity, individuals can be grouped into four different drug metabolizer phenotypes: ultra-rapid metabolizers (UM), normal (extensive) metabolizers (EM), intermediate metabolizers (IM), and poor metabolizers (PM) (Ravyn et al., 2013; Gopisankar 2017). As the frequency of CYP2D6 alleles differs among races and populations, the drug metabolism phenotypes distributions are different among ethnicities (Gopisankar 2017).

Researchers have extensively explored the association between CYP2D6 genetic variability and TD development; however, the results are contradictory (Table 1 and Supplementary Table S2). Some studies did not show an association between TD and CYP2D6*1, CYP2D6*2, CYP2D6*3, CYP2D6*4, CYP2D6 ${ }^{\star} 5$, CYP2D6*6, CYP2D6 ${ }^{\star} 15 a$, and CYP2D6*17 (Arthur et al., 1995; Armstrong et al., 1997; Ohmori et al., 1998; Ohmori et al., 1999; 
Brockmöller et al., 2002; Lohmann et al., 2003), but some studies indicated a statistically significant or borderline association between CYP2D6 alleles and TD. A statistically significant association between $C Y P 2 D 6^{\star} 10$ and $\mathrm{TD}$, both before and after adjustment for clinical variables, was reported in a cohort of 100 Japanese patients with schizophrenia (Ohmori et al., 1998). Similarly, the $\mathrm{T}$ allele of the $C Y P 2 D 6^{\star} 10$ was associated with TD development in a different study (Fu et al., 2006). Another study reported potential associations between $C Y P 2 D 6^{*}$, CYP2D6*4, and CYP2D6*5 variants and TD occurrence. According to the results, heterozygotes in particular presented with a higher risk for TD development (Kapitany et al., 1998). Similarly, heterozygotes for $C Y P 2 D 6^{*} 3$ or $C Y P 2 D 6^{\star} 4$ had a higher chance for TD development (Jaanson et al., 2002). A report by Andreassen et al. (1997) investigated $C Y P 2 D 6^{*} 1, C Y P 2 D 6^{*}$, CYP2D6*4, CYP $2 D 6^{*} 5, C Y P 2 D 6^{*} 6$ and $C Y P 2 D 6^{*} 7$ variants in 100 schizophrenic patients from South-East Scotland. They showed a positive correlation between PM and TD severity (Andreassen et al., 1997). Koola et al., 2014 explored the impact of CYP2D6*3,CYP2D6*4,CYP2D6*5 and CYP2D6*41 genetic variability on TD occurrence and revealed that an increase in the number of functional CYP2D6 alleles is associated with TD risk (Koola et al., 2014). One of the latest studies with a slightly higher number of participants showed that $C Y P 2 D 6^{\star} 4$ was associated with a higher risk for limbo-truncal TD (Ivanova et al., 2016a). Additionally, a study done by $\mathrm{Lu}$ et al. reported that CYP2D6 UM and PM have a higher risk for TD development and higher severity of TD compared to IMs and EMs. This is the first study that suggested that both extremes of CYP2D6 metabolic capacity have increased TD risk instead of PM only (Lu et al., 2020). Lastly, a meta-analysis that included 12 pharmacogenetic studies aimed to identify the potential association between CYP2D6 alleles and TD development. A statistically significant association was observed between loss of function CYP2D6 alleles and increased risk for TD development in patients with schizophrenia treated with antipsychotics (Patsopoulos et al., 2005).

Differences in $C Y P 2 D 6^{\star} 10$ allele frequency were also reported in gender analysis studies. More specifically, the frequency of $C Y P 2 D 6^{*} 10$ was higher in female than in male patients with schizophrenia that experienced TD (Lam et al., 2001). Additionally, the risk for developing TD was higher in male carriers of a non-functional or partially functional allele, for instance $C Y P 2 D 6^{\star} 5, C Y P 2 D 6^{\star} 10 B, C Y P 2 D 6^{\star} 14$, and $C Y P 2 D 6^{\star} 41$ than in wild type allele carriers (Nikoloff et al., 2002). Notably, smoking is another important variable, given that a study that considered interactions between genotypes and smoking status, indicated that most American smokers treated with antipsychotics and being carriers of the CYP $2 D 6^{\star} 1{ }^{\star} 3$, ${ }^{\star} 4$ genotypes had TD (Ellingrod et al., 2002).

The impact of CYP1A2 genetic variability in TD also yielded conflicting results. No association was recorded between TD and CYP1A2*1F (Schulze et al., 2001; Chong et al., 2003b; Matsumoto et al., 2004a) or CYP1A2*1C (Matsumoto et al., 2004a). However, higher AIMS scores were reported in $C Y P 1 A 2^{*} 1 F$ CC homozygotes (Basile et al., 2000; Ivanova et al., 2015). Two additional studies confirmed the association of the $C Y P 1 A 2^{\star} 1 F$ genotype with TD development (Fu et al., 2006; Ivanova et al., 2016a). Interestingly, carriers of CYP1A2* $1 \mathrm{C}$ variant allele who were smokers and received only FGAs had increased severity of TD (Tiwari et al., 2005a).

Finally, it was reported that the CYP17A1 rs743572 affects the development of TD since carriers of the CC genotype had a lower risk for TD occurrence (Ivanova et al., 2014). Additionally, the same single nucleotide polymorphism (SNP) was associated with the risk for abnormal orofacial and distal involuntary movements in schizophrenia patients (Segman et al., 2002a).

Among transporters important for pharmacokinetics of antipsychotics only the $A B C B 1$ was assessed. It was reported that there is no association between the $A B C B 1$ rs1045642 or rs1922242 and TD development (de Leon et al., 2005; De Luca et al., 2009). Notably, the haplotypes of rs1045642 and rs1922242 may play a role in the severity of $\mathrm{TD}$, given that $\mathrm{T}-\mathrm{A}$ and $\mathrm{T}-\mathrm{T}$ haplotypes were associated with lower and higher AIMS scores, respectively (De Luca et al., 2009).

\section{PHARMACOGENOMIC STUDIES FOCUSING ON THE ASSOCIATION BETWEEN TARDIVE DYSKINESIA AND GENES INVOLVED IN THE PHARMACODYNAMICS}

\subsection{Dopamine Receptor Genes}

Dopamine is a neurotransmitter that has an important role in human brain functions. Its dysregulation has been found to cause psychosis and mood disorders, as well as movement disorders, such as Parkinson's disease and Huntington's disease (GoodeRomero et al., 2020). A variety of commonly prescribed antipsychotic drugs, such as aripiprazole, cariprazine and brexpiprazole, are partial agonists of dopamine receptors. The involvement of dopamine receptors in TD development has received much attention over the years (Table 2) due to their crucial role in antipsychotics' mechanism of action (Wang et al., 2018; Azorin and Simon 2019). All of the studies are presented in this chaptercan be found in the Supplementary Table S2.

D1 dopamine receptor is mainly found in the central nervous system. It regulates neuronal growth and development, and mediates behavioral and cognitive functions by stimulating adenylyl cyclase and activating cyclic AMP-dependent protein kinases (Dolzan et al., 2007). DRD1 rs5326, rs4532 and rs265975 polymorphisms have been investigated as potential TD biomarkers. Schizophrenia patients with the DRD1 rs4532 CC genotype had increased chance for TD development, while the rest of the studied polymorphisms did not reach statistical significance (Lai et al., 2011b). Nevertheless, the association between rs4532 and TD was not supported in a cohort of Indian patients with TD (Srivastava et al., 2006).

Dopamine receptor D2 protein inhibits adenylyl cyclase activity. Genetic variability of DRD2 has been associated with schizophrenia and response to both FGAs and SGAs, as well as myoclonus dystonia (Klein et al., 1999; Wu et al., 2005; Fan et al., 2010; Wang et al., 2018). Studied DRD2 polymorphisms which 
TABLE 2 | Genetic variability of dopamine receptors and its association with TD.

\begin{tabular}{|c|c|c|c|}
\hline Genes & Genetic variations & Association & References \\
\hline \multirow[t]{8}{*}{ DRD1 } & rs4532 & Yes & Lai et al. (2011b) \\
\hline & & No & Srivastava et al. (2006) \\
\hline & rs5326 & No & Lai et al. (2011b) \\
\hline & rs265975 & No & Lai et al. (2011b) \\
\hline & rs5330 & No & Srivastava et al. (2006) \\
\hline & rs5331 & No & Srivastava et al. (2006) \\
\hline & rs13306309 & No & Srivastava et al. (2006) \\
\hline & rs686 & No & Srivastava et al. (2006) \\
\hline \multirow[t]{24}{*}{ DRD2 } & rs1800497 & Yes & Chen et al. (1997); Liou et al. (2006); Zai et al. (2007a); Bakker et al. (2008) \\
\hline & & No & $\begin{array}{l}\text { Hori et al. (2001); Kaiser et al. (2002); Segman et al. (2003); Srivastava et al. (2006); Park et al. (2011); } \\
\text { Koning et al. (2012); Lu et al. (2018) }\end{array}$ \\
\hline & rs6275 & Yes & Zai et al. (2007b) \\
\hline & & No & Park et al. (2011) \\
\hline & rs6277 & Yes & Zai et al. (2007b) \\
\hline & & No & Koning et al. (2012); Lu et al. (2018) \\
\hline & rs1079597 & Yes & Liou et al. (2006) \\
\hline & & No & Kaiser et al. (2002) \\
\hline & rs1799732 & No & $\begin{array}{l}\text { Hori et al. (2001); Kaiser et al. (2002); Segman et al. (2003); de Leon et al. (2005); Srivastava et al. } \\
\text { (2006); Liou et al. (2006); Zai et al. (2007b); Park et al. (2011); Koning et al. (2012) }\end{array}$ \\
\hline & rs1799978 & No & Kaiser et al. (2002) \\
\hline & rs1800496 & No & Kaiser et al. (2002); Zai et al. (2007b) \\
\hline & rs1800497 & No & Zai et al. (2007b) \\
\hline & rs1800498 & No & (Kaiser et al., 2002; Liou et al., 2006; Zai et al., 2007b; Park et al., 2011; Koning et al., 2012) \\
\hline & rs1800499 & No & Kaiser et al. (2002) \\
\hline & rs1801028 & No & $\begin{array}{l}\text { Hori et al. (2001); Kaiser et al. (2002); Segman et al. (2003); Chong et al. (2003a); de Leon et al. (2005); } \\
\text { Srivastava et al. (2006); Liou et al. (2006); Park et al. (2011) }\end{array}$ \\
\hline & rs4648317 & No & Zai et al. (2007b) \\
\hline & rs1079598 & No & Zai et al. (2007b) \\
\hline & rs2242591 & No & Zai et al. (2007b) \\
\hline & rs2242592 & No & Zai et al. (2007b) \\
\hline & rs2242593 & No & Zai et al. (2007b) \\
\hline & Val96Ala & No & Kaiser et al. (2002) \\
\hline & rs2234689 & No & Srivastava et al. (2006) \\
\hline & rs17294542 & No & Srivastava et al. (2006) \\
\hline & rs1125394 & No & Zai et al. (2007b) \\
\hline \multirow[t]{26}{*}{ DRD3 } & rs6280 & Yes & $\begin{array}{l}\text { Steen et al. (1997); Segman et al. (1999); Segman et al. (2002a); Basile et al. (1999); Liao et al. (2001); } \\
\text { Lerer et al. (2002); Woo et al. (2002); de Leon et al. (2005); Al Hadithy et al. (2009) }\end{array}$ \\
\hline & & No & $\begin{array}{l}\text { Gaitonde et al. (1996); Rietschel et al. (2000); Løvlie et al. (2000); Segman et al., 2000; Garcia-Barceló } \\
\text { et al. (2001); Chong et al. (2003a); Srivastava et al. (2006); Zai et al. (2009b); Utsunomiya et al., 2012; } \\
\text { Koning et al. (2012) }\end{array}$ \\
\hline & rs9817063 & No & Bakker et al. (2012); Ivanova et al. (2012b) \\
\hline & rs2134655 & No & Zai et al. (2009b); Bakker et al. (2012); Ivanova et al. (2012b) \\
\hline & rs963468 & No & Bakker et al. (2012); Ivanova et al. (2012b) \\
\hline & rs324035 & No & (Bakker et al., 2012; Ivanova et al., 2012b) \\
\hline & rs3773678 & No & Bakker et al. (2012); Ivanova et al. (2012b) \\
\hline & rs167771 & No & Bakker et al. (2012); Ivanova et al. (2012b) \\
\hline & rs11721264 & No & Bakker et al. (2012); Ivanova et al. (2012b) \\
\hline & rs167770 & No & Zai et al. (2009b); Bakker et al. (2012); Ivanova et al. (2012b) \\
\hline & rs7633291 & No & Zai et al. (2009b); Bakker et al. (2012); Ivanova et al. (2012b) \\
\hline & rs1800828 & No & Bakker et al. (2012); Ivanova et al. (2012b) \\
\hline & rs3732782 & No & Zai et al. (2009b) \\
\hline & rs905568 & No & Srivastava et al. (2006); Zai et al. (2009b) \\
\hline & rs7620754 & No & Zai et al. (2009b) \\
\hline & rs7616367 & No & Zai et al. (2009b) \\
\hline & rs7611535 & No & Zai et al. (2009b) \\
\hline & rs1394016 & No & Zai et al. (2009b) \\
\hline & rs9825563 & No & Zai et al. (2009b) \\
\hline & rs1800828 & No & Zai et al. (2009b) \\
\hline & rs2399496 & No & Zai et al. (2009b) \\
\hline & rs2087017 & No & Zai et al. (2009b) \\
\hline & rs1025398 & No & Zai et al. (2009b) \\
\hline & rs3732782, rs905568, rs7620754 & Yes - haplotype & Zai et al. (2009b) \\
\hline & rs324026 & No & Srivastava et al. (2006) \\
\hline & rs1503670 & No & Srivastava et al. (2006) \\
\hline
\end{tabular}


TABLE 2 | (Continued) Genetic variability of dopamine receptors and its association with TD.

\begin{tabular}{|c|c|c|c|}
\hline Genes & Genetic variations & Association & References \\
\hline & biallelic STR & No & Srivastava et al. (2006) \\
\hline \multirow[t]{10}{*}{ DRD4 } & 120-bp tandem duplication & Yes & Srivastava et al. (2006) \\
\hline & & No & Segman et al. (2003) \\
\hline & rs11246226 & No & Zai et al. (2009a) \\
\hline & 48 bp VNTR exon 3 & No & Segman et al. (2003); Srivastava et al. (2006); Zai et al. (2009a) \\
\hline & rs936465 & No & Zai et al. (2009a) \\
\hline & rs3758653 & No & Zai et al. (2009a); Bakker et al. (2012); Ivanova et al. (2012b) \\
\hline & $\begin{array}{l}\text { rs3758653, rs916457, rs762502, } \\
\text { rs11246226 }\end{array}$ & Yes-haplotype & Zai et al. (2009a) \\
\hline & rs762502 & No & Zai et al. (2009a) \\
\hline & rs916457 & No & Zai et al. (2009a) \\
\hline & rs1800955 & No & Srivastava et al. (2006) \\
\hline
\end{tabular}

did not reach statistical significance in neither allelic nor genotypic level include rs1801028 (Hori et al., 2001; Kaiser et al., 2002; de Leon et al., 2005; Srivastava et al., 2006; Park et al., 2011), rs1800497 (Hori et al., 2001; Kaiser et al., 2002; Segman et al., 2003; Srivastava et al., 2006; Park et al., 2011; Koning et al., 2012; Lu et al., 2018), rs1799732 (Hori et al., 2001; Kaiser et al., 2002; Segman et al., 2003; de Leon et al., 2005; Liou et al., 2006; Srivastava et al., 2006; Zai et al., 2007b; Park et al., 2011; Koning et al., 2012), rs1801028 (Hori et al., 2001; Kaiser et al., 2002; Chong et al., 2003a; Segman et al., 2003; de Leon et al., 2005; Liou et al., 2006; Srivastava et al., 2006; Park et al., 2011), rs1799978, rs1079597, p. Val96Ala, rs1800499, rs1800496 (Kaiser et al., 2002), rs1800498 (Kaiser et al., 2002; Liou et al., 2006; Zai et al., 2007b; Park et al., 2011; Koning et al., 2012), rs2234689, and rs17294542 (Srivastava et al., 2006). However, an older study performed in patients with schizophrenia indicated that rs1800497 might affect the development of TD, given that the A2 allele and A2/A2 genotype were more frequent in female patients with TD (Chen et al., 1997). In addition, two metaanalyses and a comparative study suggested that the A2 allele and the A2/A2 genotype of rs 1800497 was associated with increased TD risk (Liou et al., 2006; Zai et al., 2007a; Bakker et al., 2008). Regarding rs1079597, B2 allele and B2/B2 genotype has been associated with increased TD risk (Liou et al., 2006). A metaanalysis that included 1256 patients with schizophrenia concluded that rs1799732 was not associated with TD (Zai et al., 2007a). Rs6275 (Park et al., 2011) and rs6277 (Koning et al., 2012) gave negative results for potential association with TD. Nonetheless, the study of Zai et al. found that rs6277 T allele and rs6275 C allele frequencies were lower in TD patients as compared to patients with schizophrenia without TD (Zai et al., 2007b).

Dopamine D3 receptor is associated with cognitive, emotional, and endocrine functions due to its localization in the limbic areas of the brain. It signals through $G$ proteins which inhibit adenylyl cyclase. Pathologies associated with $D R D 3$ polymorphisms include schizophrenia and hereditary essential tremor (Jeanneteau et al., 2006; Nunokawa et al., 2010; Sáiz et al., 2010). Many scientific groups focused on the association between DRD3 rs6280 and TD, which gave conflicting results. Some studies indicated no association with TD development, on neither allelic nor genotypic level (Gaitonde et al., 1996; Løvlie et al., 2000; Rietschel et al., 2000; Segman et al., 2000; Garcia-Barceló et al., 2001; Chong et al., 2003a; Srivastava et al., 2006; Zai et al., 2009b; Koning et al., 2012; Utsunomiya et al., 2012). Several meta-analyses have also been conducted, which either observed a significant contribution of the p.9Gly allele to the higher risk for TD (Lerer et al., 2002; Bakker et al., 2006) or failed to prove a significant association (Tsai et al., 2010). There was no association on the genotypic level, probably due to the small effect size and ethnic diversity. The authors concluded that DRD3 rs6280 might be associated with TD, but caution is required in interpreting this result (Bakker et al., 2006). However, some studies showed a correlation between TD with either the p.9Gly allele (Steen et al., 1997; Lerer et al., 2002; Bakker et al., 2006), or p.9Gly homozygotes (Basile et al., 1999; Woo et al., 2002) and heterozygotes (Liao et al., 2001). Additionally, DRD3 rs6280 was associated with a subtype of TD, namely limb-truncal dyskinesia (Al Hadithy et al., 2009). Other DRD3 polymorphisms that have been studied but indicated no association with TD include rs3732782, rs905568, rs7620754, rs7616367, rs7611535, rs1394016, rs9825563, rs1800828, rs2399496, rs2087017, rs1025398, rs9817063, rs2134655, rs963468, rs324035, rs3773678, rs167771, rs11721264, rs167770, rs7633291 and rs1800828 (Zai et al., 2009b; Bakker et al., 2012; Ivanova et al., 2012b) rs324026, rs 1503670 and biallelic STR (Srivastava et al., 2006). However, it is important to mention that the study of Zai et al. and his colleagues reported an association between the DRD3 haplotype of rs3732782, rs905568, and rs7620754 and TD and they provided evidence of interaction between $B D N F$ and $D R D 3$ polymorphisms.

Finally, DRD4 rs3758653, rs11246226, 48 bp VNTR exon 3, rs936465, rs3758653, rs762502, rs916457, rs1800955 have been investigated in connection to $\mathrm{TD}$, but did not show any correlation (Segman et al., 2003; Srivastava et al., 2006; Zai et al., 2009a; Bakker et al., 2012; Ivanova et al., 2012b).

However, association between the haplotype of rs3758653, rs916457, rs762502, rs11246226 and TD was reported (Zai et al., 2009a), as well as association between the $120 \mathrm{bp}$ duplication marker in DRD4 and TD in genotypic level (Srivastava et al., 2006), which was not replicated (Segman et al., 2003). All of the studies are presented in this chaptercan be found in the Supplementary Table S2. 
TABLE 3 | Genetic variability of serotonin receptors and its association with TD.

\begin{tabular}{|c|c|c|c|}
\hline Genes & Genetic variations & Association & References \\
\hline \multirow[t]{5}{*}{ HTR1A } & rs6295 & No & Pozhidaev et al. (2020) \\
\hline & rs1364043 & No & Pozhidaev et al. (2020) \\
\hline & rs10042486 & No & Pozhidaev et al. (2020) \\
\hline & rs1800042 & No & Pozhidaev et al. (2020) \\
\hline & rs749099 & No & Pozhidaev et al. (2020) \\
\hline \multirow[t]{3}{*}{ HTR1B } & rs6298 & No & Pozhidaev et al. (2020) \\
\hline & rs6296 & No & Pozhidaev et al. (2020) \\
\hline & rs130058 & No & Pozhidaev et al. (2020) \\
\hline \multirow[t]{9}{*}{ HTR2A } & rs1928040 & Yes & Pozhidaev et al. (2020) \\
\hline & rs6311 & Yes & Segman et al. (2001); Boke et al. (2007) \\
\hline & & No & Basile et al. (2001); Herken et al. (2003); Al Hadithy et al. (2009); Pozhidaev et al. (2020) \\
\hline & rs6313 & Yes & Segman et al. (2001); Tan et al. (2001); Hsieh et al. (2011) \\
\hline & & No & Basile et al. (2001); Herken et al. (2003); Koning et al. (2012); Pozhidaev et al. (2020) \\
\hline & rs6314 & No & Basile et al. (2001); Segman et al. (2001); Koning et al. (2012); Pozhidaev et al. (2020) \\
\hline & rs7997012 & No & Pozhidaev et al. (2020) \\
\hline & rs9316233 & No & Pozhidaev et al. (2020) \\
\hline & rs2224721 & No & Pozhidaev et al. (2020) \\
\hline \multirow[t]{12}{*}{ HTR2C } & rs518147 & Yes & Zhang et al. (2002a) \\
\hline & rs6318 & Yes & Segman et al. (2000); Al Hadithy et al. (2009) \\
\hline & & No & Hsieh et al. (2011); Ivanova et al. (2012b); Koning et al. (2012); Pozhidaev et al. (2020) \\
\hline & rs1801412 & Yes & Pozhidaev et al. (2020) \\
\hline & & No & Bakker et al. (2012); Pozhidaev et al. (2020) \\
\hline & rs4911871 & No & Bakker et al. (2012) \\
\hline & rs12858300 & No & Bakker et al. (2012); Pozhidaev et al. (2020) \\
\hline & rs17326429 & No & Bakker et al. (2012); Pozhidaev et al. (2020) \\
\hline & rs3813929 & No & Zhang et al. (2002a); Ivanova et al. (2012b); Koning et al. (2012); Pozhidaev et al. (2020) \\
\hline & rs4911871 & No & Ivanova et al. (2012b); Pozhidaev et al. (2020) \\
\hline & rs569959 & No & Bakker et al. (2012); Ivanova et al. (2012b); Pozhidaev et al. (2020) \\
\hline & rs5946189 & No & Bakker et al. (2012); Pozhidaev et al. (2020) \\
\hline \multirow[t]{3}{*}{ HTR3A } & rs1062613 & No & Kang et al. (2013); Pozhidaev et al. (2020) \\
\hline & rs33940208 & No & Pozhidaev et al. (2020) \\
\hline & rs1176713 & No & Pozhidaev et al. (2020) \\
\hline HTR3B & rs1176744 & No & Pozhidaev et al. (2020) \\
\hline HTR6 & rs1805054 & No & Ohmori et al. (2002); Segman et al. (2003); Pozhidaev et al. (2020) \\
\hline
\end{tabular}

\subsection{Serotonin Receptor Genes}

Serotonin is a neurotransmitter, which plays a crucial role in brain pathways. Members of the 5-hydroxytryptamine receptor subfamily encode seven different receptors for serotonin. HTR2A, HTR2B and HTR2C are positively coupled with the phospholipase $\mathrm{C}$ enzyme (PLC) and have been investigated for their potential involvement in TD in many different populations (Table 3).

5-HT2A receptors are postsynaptic receptors that regulate the function of prefrontal-subcortical circuits. The 5-HT2A receptor interacts with $\mathrm{G}$ proteins and stimulates PLC to produce the intracellular second messengers sn-1,2-DAG and inositol-1,4,5trisphosphate (IP3), which control the calcium channel (McMahon et al., 2006). Mutations in the HTR2A gene were shown to be associated with susceptibility to mental disorders, such as schizophrenia, depression and obsessive-compulsive disorder, alcohol dependence and response to antidepressants (Williams et al., 1996; McMahon et al., 2006; Yasseen et al., 2010). HTR2A rs6313, rs6311 and rs6314 have been extensively studied for their potential association with TD development. According to some studies, rs6313, rs6311 and rs6314 did not reach statistical significance (Basile et al., 2001; Herken et al., 2003; Koning et al., 2012). However, HTR2A rs6313 T allele was associated with TD development (Tan et al., 2001; Hsieh et al., 2011), but on the contrary the frequency of HTR2A rs6313 TT homozygotes was higher in patients without TD (Tan et al., 2001). Additionally, it has been reported that the frequencies of HTR2A rs6313 C allele and HTR2A rs6311 G allele were higher in patients with TD. In line with that, the HTR2A rs6313 CC and HTR2A rs6311 GG (rs6311) genotypes were associated with higher AIMS scores (Segman et al., 2001) and rs6311 presented a trend of association with TD in Turkish patients with schizophrenia under prolonged exposure to antipsychotics (Boke et al., 2007). Additionally, the HTR2A rs6313 CC genotype was associated with TD development in older patients and those with limb-truncal TD (Lerer et al., 2005). The haplotype analysis of the HTR2A rs6313 and HTR2A rs6314 showed significant associations with TD (Lerer et al., 2005). Finally, HTR2A rs1928040 was associated with the orofacial type of TD (Pozhidaev et al., 2020).

Regarding HTR2C genetic variability rs6318 has been thoroughly studied over the years. Two studies indicated no association with TD (Hsieh et al., 2011; Koning et al., 2012). However, a study published in 2000 showed that the frequency of the Ser allele was more frequent in patients with TD (Segman et al., 2000). Additionally, HTR2C rs6318 was associated with 
TABLE 4 | Genetic variability of other neurotransmitter receptors and their association with TD.

\begin{tabular}{|c|c|c|c|}
\hline Genes & Genetic variations & Association & References \\
\hline \multirow[t]{6}{*}{ CHRM1 } & rs2075748 & No & Boiko et al. (2020) \\
\hline & rs544978 & No & Boiko et al. (2020) \\
\hline & rs2067477 & No & Boiko et al. (2020) \\
\hline & rs2067479 & No & Boiko et al. (2020) \\
\hline & rs2186410 & No & Boiko et al. (2020) \\
\hline & rs542269 & No & Boiko et al. (2020) \\
\hline \multirow[t]{8}{*}{ CHRM2 } & rs2061174 & Yes & Boiko et al. (2020) \\
\hline & rs1824024 & Yes & Boiko et al. (2020) \\
\hline & rs324650 & No & Boiko et al. (2020) \\
\hline & rs2350780 & No & Boiko et al. (2020) \\
\hline & rs7810473 & No & Boiko et al. (2020) \\
\hline & rs2350786 & No & Boiko et al. (2020) \\
\hline & rs324640 & No & Boiko et al. (2020) \\
\hline & rs1378650 & No & Boiko et al. (2020) \\
\hline \multirow[t]{20}{*}{ CNR1 } & rs806374 & Yes & Tiwari et al. (2012) \\
\hline & rs12720071 & No & Tiwari et al. (2012) \\
\hline & rs1049353 & No & Tiwari et al. (2012) \\
\hline & rs80639 & No & Tiwari et al. (2012) \\
\hline & rs806370 & No & Tiwari et al. (2012) \\
\hline & rs806368 & No & Tiwari et al. (2012) \\
\hline & rs806375 & No & Tiwari et al. (2012) \\
\hline & rs806377 & No & Tiwari et al. (2012) \\
\hline & rs806378 & No & Tiwari et al. (2012) \\
\hline & rs2023239 & No & Tiwari et al. (2012) \\
\hline & rs806380 & No & Tiwari et al. (2012) \\
\hline & rs806381 & No & Tiwari et al. (2012) \\
\hline & rs7752758 & No & Tiwari et al. (2012) \\
\hline & rs12528858 & No & Tiwari et al. (2012) \\
\hline & rs12205430 & No & Tiwari et al. (2012) \\
\hline & rs6914429 & No & Tiwari et al. (2012) \\
\hline & rs2180619 & No & Tiwari et al. (2012) \\
\hline & rs754387 & No & Tiwari et al. (2012) \\
\hline & rs9450902 & No & Tiwari et al. (2012) \\
\hline & rs10485170 & No & Tiwari et al. (2012) \\
\hline GABRB2 & rs918528 & No & Son et al. (2014) \\
\hline GABRG3 & rs2061051 & No & Son et al. (2014) \\
\hline \multirow[t]{19}{*}{ GRIN2A } & rs7206256 & Yes & Ivanova et al. (2012b) \\
\hline & rs1345423 & Yes & Ivanova et al. (2012b); Ivanova et al. (2016b) \\
\hline & & No & Bakker et al. (2012) \\
\hline & rs7190619 & Yes & Ivanova et al. (2012b) \\
\hline & & No & Bakker et al. (2012) \\
\hline & rs9788936 & Yes & Ivanova et al. (2012b) \\
\hline & & No & Bakker et al. (2012) \\
\hline & rs11646587 & Yes & Ivanova et al. (2012b) \\
\hline & & No & Bakker et al. (2012) \\
\hline & rs9921541 & No & Bakker et al. (2012); Ivanova et al. (2012b) \\
\hline & rs7192557 & No & Bakker et al. (2012); Ivanova et al. (2012b) \\
\hline & rs8049651 & No & Bakker et al. (2012); Ivanova et al. (2012b) \\
\hline & rs7196095 & No & Bakker et al. (2012); Ivanova et al. (2012b) \\
\hline & rs11866328 & No & Bakker et al. (2012); Ivanova et al. (2012b) \\
\hline & rs4782039 & No & Bakker et al. (2012); Ivanova et al. (2012b) \\
\hline & rs11644461 & No & Bakker et al. (2012); Ivanova et al. (2012b) \\
\hline & rs9989388 & No & Bakker et al. (2012); Ivanova et al. (2012b) \\
\hline & rs8057394 & No & Bakker et al. (2012); Ivanova et al. (2012b) \\
\hline & rs1650420 & No & Bakker et al. (2012); Ivanova et al. (2012b) \\
\hline \multirow[t]{9}{*}{ GRIN2B } & rs2192970 & Yes & Ivanova et al. (2012b) \\
\hline & & No & Bakker et al. (2012) \\
\hline & rs1805481 & No & Ivanova et al. (2012b) \\
\hline & rs7313149 & No & Bakker et al. (2012); Ivanova et al. (2012b) \\
\hline & rs2300242 & No & Bakker et al. (2012); Ivanova et al. (2012b) \\
\hline & rs10845838 & No & Bakker et al. (2012); Ivanova et al. (2012b) \\
\hline & rs12300851 & No & Bakker et al. (2012); Ivanova et al. (2012b) \\
\hline & rs220599 & No & Bakker et al. (2012); Ivanova et al. (2012b) \\
\hline & rs10772715 & No & Bakker et al. (2012); Ivanova et al. (2012b) \\
\hline
\end{tabular}

(Continued on following page) 
TABLE 4 | (Continued) Genetic variability of other neurotransmitter receptors and their association with TD.

\begin{tabular}{|c|c|c|c|}
\hline Genes & Genetic variations & Association & References \\
\hline & rs12827536 & No & Bakker et al. (2012); Ivanova et al. (2012b) \\
\hline OPRD1 & $921 \mathrm{~T} / \mathrm{C}$ & No & Ohmori et al. (2001) \\
\hline OPRM1 & rs1799971 & Yes & Ohmori et al. (2001) \\
\hline
\end{tabular}

limb-truncal but not with orofaciolingual dyskinesia in the Russian population (Al Hadithy et al., 2009). Another studied polymorphism of HTR2C rs518147 was more frequent in patients with schizophrenia that experienced TD (Zhang et al., 2002a; Koning et al., 2012). Other HTR2C polymorphisms were studied, such as rs569959, rs17326429, rs12858300, rs4911871, rs5946189, rs1801412 (Bakker et al., 2012), and rs3813929 (Zhang et al., 2002a; Koning et al., 2012), but no association with TD was recorded. However, HTR2C rs1801412 was significantly associated with the orofacial type of TD in women (Pozhidaev et al., 2020).

Lastly, there are three studies that focused on HTR6 rs1805054. No association with TD was reported in Japanese, Ashkenazi, non-Ashkenazi and Caucasian schizophrenia patients (Ohmori et al., 2002; Segman et al., 2003; Pozhidaev et al., 2020). All of the studies are presented in this chaptercan be found in the Supplementary Table S2.

\subsection{Other Neurotransmission Receptors}

Several other neurotransmitters and their receptors may also play a role in the development of TD (Table 4).

The glutamate system has also been examined for potential involvement in TD pathophysiology. GRIN2A encodes the $\mathrm{N}$-methyl-d-aspartate (NMDA) receptor, which belongs to the glutamate-gated ion channel family. These receptors are involved in crucial signaling pathways, and their dysregulation is associated with epilepsy, cognitive and speech deficits, and intellectual disability (Endele et al., 2010; Lemke et al., 2013; Lesca et al., 2013). Three studies have investigated the potential role of NMDA glutamate receptor genes, GRIN2A and GRIN2B in TD (Bakker et al., 2012; Ivanova et al., 2012b; Ivanova et al., 2016b). Except for GRIN2A rs7206256, which was associated with orofacial TD (Ivanova et al., 2012b), conflicting results emerged for GRIN2A rs1345423, rs7190619, rs9788936 and rs11646587 (Bakker et al., 2012; Ivanova et al., 2012b; Ivanova et al., 2016b). The same stands for GRIN2B rs2192970 (Bakker et al., 2012; Ivanova et al., 2012b), while the rest of the studied polymorphisms were not associated with TD (Bakker et al., 2012; Ivanova et al., 2012b; Ivanova et al., 2016b). The role of GABA receptor genes GABRB2 and GABRG3 in TD has been investigated, but no significant associations were reported for the studied polymorphisms. However, gene-gene interactions between GABRB2, GABRG3, and SCL6A11 and susceptibility to TD highlighted the importance of the GABA receptor signaling pathway (Son et al., 2014).

Muscarinic receptors participate in various cellular responses such as inhibition of adenylate cyclase, degeneration of phosphoinositide, and control of potassium channel. These receptors can influence the function of the central and peripheral nervous system through acetylcholine-induced signaling (Luo et al.,
2005). Blocking muscarinic receptors with anticholinergic drugs is a common therapeutic approach for treatment of the drug-induced parkinsonism and dystonia. Assessment of the association of muscarinic cholinergic receptor 1 (CHRM1) and 2 (CHRM2) genetic variability with TD development showed a trend towards CHRM2 rs2061174 and rs1824024 effect on TD risk (Boiko et al., 2020). Interestingly, CHRM2 is involved in neurophysiological processes, mood disorders, alcohol and nicotine abuse (Luo et al., 2005; Dick et al., 2007; Mobascher et al., 2010).

Opioid receptors can act as dopamine regulators and target endogenous opioid peptides and analgesics. Genetic variability of opioid receptors has been associated with substance abuse and addiction, as well as schizophrenia (Deb et al., 2010; Serý et al., 2010). Genetic variability of OPRD1 indicated no association with TD. However, OPRM1 rs1799971 showed to be a promising biomarker of TD development since the frequency of the $G$ allele was lower in patients with TD (Ohmori et al., 2001).

Cannabinoid receptors are members of the G-protein coupled receptor family, which inhibits adenylate cyclase activity in a dosedependent way. Cannabinoid use induces symptoms, such as anxiety, memory loss and chronic pain, which is associated with cannabinoid receptors 1 (CNR1) and 2 (CNR2) (Oddi et al., 2012; Hua et al., 2016). Apart from their association with cannabis dependence and abuse, and heroin addiction, cannabinoid receptors have also been related to antipsychotic-induced weight gain in patients with schizophrenia (Proudnikov et al., 2010; Tiwari et al., 2010; Arias Horcajadas et al., 2021). The potential role of CNR1 as an activator in movement inhibition has also been investigated. The findings indicate an association between the CNR1 rs806374 CC genotype with both the development and severity of TD. However, more studies are needed to replicate this association (Tiwari et al., 2012).All of the studies are presented in this chaptercan be found in the Supplementary Table S2.

\subsection{Neurotransmitter Transporters}

SLC18A2 encodes the vesicular monoamine transporter 2 protein, a transmembrane protein that regulates neurotransmission through transportation of monoamines, such as dopamine, serotonin, and norepinephrine, into the intracellular vesicles. Psychiatric disorders like schizophrenia, as well as movement disorders (Rilstone et al., 2013), nicotine and alcohol dependence (Schwab et al., 2005) and antidepressant response (Crowley et al., 2008) have been associated with SLC18A2 polymorphisms. SLC18A2 rs363390, rs14240, rs1860404, rs2015586 (Zai et al., 2013), and rs363224 were all associated with TD development (Zai et al., 2013; Lu et al., 2018).

SLC6A4 encodes the serotonin transporter (5-HTT), a membrane protein that transports serotonin from the synaptic 
TABLE 5 | Genetic variability of neurotransmitter transporters and its associations with TD.

\begin{tabular}{|c|c|c|c|}
\hline Genes & Genetic variations & Association & References \\
\hline \multirow[t]{9}{*}{ SLC18A2 } & rs363390 & Yes & Zai et al. (2013) \\
\hline & rs14240 & Yes & Zai et al. (2013) \\
\hline & rs1860404 & Yes & Zai et al. (2013) \\
\hline & rs2015586 & Yes & Zai et al. (2013) \\
\hline & rs363224 & Yes & Zai et al. (2013); Lu et al. (2018) \\
\hline & rs363285 & No & Zai et al. (2013) \\
\hline & rs363393 & No & Zai et al. (2013) \\
\hline & rs2072362 & No & Zai et al. (2013) \\
\hline & rs2244249 & No & Zai et al. (2013) \\
\hline SLC6A4 & 5-HTTLPR VNTR (5-HTT) & No & Chong et al. (2000); Herken et al. (2003); Segman et al. (2003); Hsieh et al. (2011) \\
\hline \multirow[t]{2}{*}{ SLC6A3 } & $40 \mathrm{bp}$ VNTR & No & Segman et al. (2003); Srivastava et al. (2006) \\
\hline & G2319A & No & Segman et al. (2003) \\
\hline SLC6A11 & rs4684742 & Yes & Son et al. (2014) \\
\hline
\end{tabular}

TABLE 6 | Genetic variability of neurotransmitter biosynthesis and degradation pathways and its association with TD.

\begin{tabular}{|c|c|c|c|}
\hline $\begin{array}{l}\text { Genes } \\
\text { examined }\end{array}$ & Genetic variations & Association & References \\
\hline \multirow[t]{10}{*}{ COMT } & rs4680 & Yes & Srivastava et al. (2006); Bakker et al. (2008) \\
\hline & & No & $\begin{array}{l}\text { Herken et al. (2003); Matsumoto et al. (2004a); Lai et al. (2005); Zai et al. (2010b); Koning et al. (2012); } \\
\text { Li et al. (2013); Lv et al. (2016) }\end{array}$ \\
\hline & rs4818 & Yes & Srivastava et al. (2006) \\
\hline & & No & Zai et al. (2010b) \\
\hline & rs165599 & Yes & Zai et al. (2010b) \\
\hline & rs737865 & No & Zai et al. (2010b) \\
\hline & rs6269 & No & Zai et al. (2010b) \\
\hline & rs4633 & No & Srivastava et al. (2006); Zai et al. (2010b) \\
\hline & rs2075507 & No & Srivastava et al. (2006) \\
\hline & 900 ins C 3 UTR & No & Srivastava et al. (2006) \\
\hline$D B H$ & rs72393728 & No & Sun et al. (2013); Hui et al. (2015); Hui et al. (2017) \\
\hline$M A O A$ & $\begin{array}{l}\text { 30-bp repeat in the promoter } \\
\text { region }\end{array}$ & No & Matsumoto et al. (2004b); Li et al. (2013) \\
\hline$M A O B$ & rs1799836 & No & Matsumoto et al. (2004b) \\
\hline
\end{tabular}

cleft back to presynaptic neurons. Genetic variability of SLC6A4 is associated with response to antidepressant and lithium treatment (Rybakowski et al., 2009; Tansey et al., 2012). However, studies focusing on SLC6A4 and TD development provided no evidence of association (Chong et al., 2000; Herken et al., 2003; Segman et al., 2003; Hsieh et al., 2011).

SLC6A3 encodes a dopamine transporter, member of the sodium- and chloride-dependent neurotransmitter transporter family. Variation in the number of repeats has been associated with attention-deficit hyperactivity disorder, alcohol and cocaine dependence, as well as susceptibility to Parkinson's disease (Lott et al., 2005; Kurian et al., 2009, 2011; Müller et al., 2010). The $40 \mathrm{bp}$ tandem repeat VNTR found in the 3' UTR was not associated with TD (Segman et al., 2003; Srivastava et al., 2006), and so was not the G2319A transversion either (Segman et al., 2003).

The protein encoded by SLC6A11 is a sodium-dependent transporter of GABA from synaptic cleft to surrounding glial cells leading to decreased GABA signaling. A case-control study, which included 180 patients with schizophrenia, 105 of whom experienced TD, identified an association between SLC6A11 rs4684742 and TD (Son et al., 2014) (Summarized in Table 5). All of the studies are presented in this chaptercan be found in the Supplementary Table S2.

\subsection{Neurotransmitter Biosynthesis and Degradation Pathways}

Genes involved in neurotransmitter biosynthesis and degradation have also been studied for their potential role in the development and severity of TD (Table 6). However, only rs4680 located on the catechol-O-methyltransferase gene (COMT) indicated potential association, given that $\mathrm{AA}$ and $\mathrm{AG}$ genotypes were associated with decreased TD risk in comparison with carriers of GG genotype (Srivastava et al., 2006; Bakker et al., 2008). However, additional studies failed to replicate this result (Herken et al., 2003; Matsumoto et al., 2004a; Lai et al., 2005; Zai et al., 2010b; Koning et al., 2012; Li et al., 2013; Lv et al., 2016). The AA genotype of COMT rs165599 was associated with TD and a trend of association with higher AIMS scores was also reported in a mixed cohort of Caucasians and African Americans (Zai et al., 2010b). Allelic and genotypic associations were also recorded for rs4818 in a cohort of Indian patients with 
TABLE 7 | Developmental and plasticity: genetic variations and associations with TD.

\begin{tabular}{|c|c|c|c|}
\hline Genes & Genetic variations & Association & References \\
\hline RIMS2 & rs567070433 & Yes & Alkelai et al. (2019) \\
\hline \multirow{4}{*}{ NRXN1 } & rs10490162 & No & Lanning et al. (2017) \\
\hline & rs1400882 & No & Lanning et al. (2017) \\
\hline & rs12467557 & No & Lanning et al. (2017) \\
\hline & rs1045881 & No & Lanning et al. (2017) \\
\hline \multirow[t]{4}{*}{$B D N F$} & rs6265 & No & Zai et al. (2009b); Wang et al. (2010); Zhang et al. (2012) \\
\hline & rs7934165 & No & Zai et al. (2009b) \\
\hline & rs11030104 & No & Zai et al. (2009b) \\
\hline & rs1519480 & No & Zai et al. (2009b) \\
\hline \multirow[t]{5}{*}{ DISC1 } & rs2492367 & No & Lu et al. (2018) \\
\hline & rs3738398 & No & Lu et al. (2018) \\
\hline & rs3738401 & No & Lu et al. (2018) \\
\hline & rs6675281 & No & Lu et al. (2018) \\
\hline & rs821616 & No & Lu et al. (2018) \\
\hline
\end{tabular}

schizophrenia (Srivastava et al., 2006), which was not replicated in a later study (Zai et al., 2010b) (summarized in Table 6).

Other studied genes of this category that did not reach statistical significance, include $D B H$ coding for dopamine betahydroxylase (Sun et al., 2013; Zhou et al., 2013; Hui et al., 2015, 2017), and genes coding for monoamine oxidases, $M A O A$ (Matsumoto et al., 2004b; Li et al., 2013) and $M A O B$ (Matsumoto et al., 2004b).All of the studies are presented in this chaptercan be found in the Supplementary Table S2.

\subsection{Developmental/Plasticity Factors}

ErbB4 is a tyrosin kinase receptor and among others binds neuregulins and other compounds. It plays an essential role in neurotransmission and cellular responses. It is a regulator of GABA and dopamine signaling and mediates neuroplasticity (Vullhorst et al., 2009). Genetic variability of ERBB4 has been associated with cancer, schizophrenia, and amyotrophic lateral sclerosis (Tvorogov et al., 2009; So et al., 2010; Takahashi et al., 2013). Regarding TD, ERBB4 rs839523 CC genotype was associated with a high risk of developing TD and a higher chance for severe TD in a cohort of 153 European patients with schizophrenia (Zai et al., 2019a).

The gene coding for the Protein Regulating Synaptic Membrane Exocytosis 2 (RIMS2) has also been studied, and an association between rs567070433 and TD occurrence was observed (Alkelai et al., 2019). RIMS2 encodes a protein that binds other proteins involved in neurotransmitter diffusion. Polymorphisms in this gene have been associated with degenerative lumbar scoliosis, congenital cone-rod synaptic disorder, neurodevelopmental disease, and abnormal glucose homeostasis in the elderly (Mechaussier et al., 2020).

Other genes that are involved in developmental plasticity, including BDNF (Zai et al., 2009b; Wang et al., 2010; Zhang et al.,
2012), DISC1 (Lu et al., 2018), NRXN1 (Lanning et al., 2017), and NRG1 (Zai et al., 2019a) were investigated but showed no association with TD (Table 7). All of the studies are presented in this chaptercan be found in the Supplementary Table S2.

\subsection{Oxidative Stress-Related Genes}

The role of oxidative stress-related genes has received the attention of various research groups over the years (Table 8). SOD2 belongs to the iron/manganese superoxide dismutase family and SOD2 encodes a mitochondrial protein that binds manganese ions and products of oxidative phosphorylation. SOD2 rs4880 is one of the most frequently studied polymorphisms of this gene, but conflicting results regarding its association with TD have been reported so far. Most of the studies indicated no association with TD (Zhang et al., 2002b; Zai et al., 2010a; Ivanova et al., 2012b; Koning et al., 2012), including a meta-analysis with a validation cohort of 223 patients with schizophrenia of Caucasian and African American ancestry (Zai et al., 2010a). However, an association between lower SOD2 rs4880 Ala allele frequencies in TD affected patients was recorded (Hori et al., 2000), along with a significant difference in genotypic distribution between patients with and without TD (Hori et al., 2000; Hitzeroth et al., 2007).

GSTM1 encodes a glutathione S-transferase mu 1. This enzyme conjugates with glutathione and detoxifies many electrophilic compounds, such as products of oxidative stress and drugs, influencing their toxicity and efficacy. Genetic variability of GSTM1 is associated with cancer, including brain tumors and chronic diseases, like asthma (Schwartzbaum et al., 2007; Sakoda et al., 2008; Nguyen et al., 2010; Piacentini et al., 2010). Association between GSTM1 deletion and TD development has also been observed in Caucasians taking risperidone, olanzapine, quetiapine or FGAs (de Leon et al., 2005). 
TABLE 8 | Oxidative stress pathway: genetic variations and associations with TD.

\begin{tabular}{|c|c|c|c|}
\hline Genes & Genetic variations & Association & References \\
\hline GSTM1 & GSTM1 deletion & Yes & de Leon et al. (2005) \\
\hline \multirow[t]{2}{*}{ SOD2 } & rs4880 & Yes & Hori et al. (2000); Hitzeroth et al. (2007) \\
\hline & & No & Zhang et al. (2002b); Zai et al. (2010a); Ivanova et al. (2012b); Koning et al. (2012); Bošković et al. (2013) \\
\hline NOS1 & $\mathrm{C} / \mathrm{T}$ polymorphism in exon 29 & No & Shinkai et al. (2004) \\
\hline NQO1 & rs1800566 & No & Zai et al. (2010a); Bakker et al. (2012); Ivanova et al. (2012b); Koning et al. (2012) \\
\hline GSK3B & rs334558 & No & Levchenko et al. (2019) \\
\hline GPX1 & rs1050450 & No & Shinkai et al. (2006); Bošković et al. (2013) \\
\hline \multirow[t]{2}{*}{ CAT } & rs1001179 & No & Bošković et al. (2013) \\
\hline & rs10836235 & No & Bošković et al. (2013) \\
\hline GSTT1 & GSTT1 deletion & No & de Leon et al. (2005) \\
\hline GSTP1 & rs1695 & No & Shinkai et al. (2005); Koning et al. (2012) \\
\hline
\end{tabular}

\begin{tabular}{|c|c|c|c|}
\hline Genes & Genetic variations & Association & References \\
\hline IL10 & rs1800872 & No & Sun et al. (2013) \\
\hline TNF & rs1800629 & No & Wang et al. (2012); Bošković et al. (2013) \\
\hline \multirow[t]{3}{*}{ C4A } & $C 4 A L$ & No & Zai et al. (2019b) \\
\hline & C4AS & No & Zai et al. (2019b) \\
\hline & $C 4 A$ & No & Zai et al. (2019b) \\
\hline \multirow[t]{3}{*}{$C 4 B$} & $C 4 B L$ & Yes & Zai et al. (2019b) \\
\hline & C4BS & No & Zai et al. (2019b) \\
\hline & $C 4 B$ & No & Zai et al. (2019b) \\
\hline
\end{tabular}

Other oxidative stress-related genes were also studied but indicated no association with TD. These genes include NOS1 (Shinkai et al., 2004), NQO1 (Zai et al., 2010a; Bakker et al., 2012; Ivanova et al., 2012b; Koning et al., 2012), GSK3B (Levchenko et al., 2019), GPX1 (Shinkai et al., 2006; Bošković et al., 2013), CAT (Bošković et al., 2013), GSTT1 (de Leon et al., 2005), and GSTP1 (Shinkai et al., 2005; Koning et al., 2012). All of the studies are presented in this chaptercan be found in the Supplementary Table S2.

\subsection{Inflammation and Tardive Dyskinesia}

Genes involved in inflammation have also been proposed to be associated with TD (Table 9). Genes that encode proteins involved in inflammation, such as IL10 (Sun et al., 2013), and TNF (Wang et al., 2012; Bošković et al., 2013) were studied and showed no association with TD.

Complement component 4 (C4) is part of the complement system which mediates immunity. C4 was implicated in schizophrenia pathophysiology and motor movement after injury. The investigation of copy number variations of the long (L) and short (S) forms of $C 4 A$ and $C 4 B$ in Europeans has shown a nominally significant association between $C 4 B L$ and TD severity (Zai et al., 2019b). All of the studies are presented in this chaptercan be found in the Supplementary Table S2.

\subsection{Other Genes}

Other studied candidate genes and their polymorphisms have been investigated for potential association with TD (Table 10).

Adenosine receptors are involved in many intracellular signaling pathways as homeostatic modulators of adenosine in the central nervous system. Even though there were no associations between polymorphisms of ADORA1, ADORA2A, and ADORA3 and TD (Ivanova et al., 2012a; Turčin et al., 2016), it should be mentioned that the ADORA3 CACTAT haplotype of rs3394, rs3393, rs2229155, rs35511654, rs1544223, and rs2298191 polymorphisms was associated with TD (Turčin et al., 2016).

HSPG2 encodes perlecan, a proteoglycan that binds components of the matrix and cell membrane and is involved in essential biological processes. Perlecan participates in vascularization and maintains endothelial barrier function and vascular homeostasis. Genetic variability of HSPG2 has been associated with skeletal disorders (Arikawa-Hirasawa et al., 2001, Arikawa-Hirasawa et al., 2002). HSPG2 polymorphisms were not associated with TD in several different studies (Bakker et al., 2012; Ivanova et al., 2012b; Greenbaum et al., 2012). However, the assessment of HSPG2 rs2445142 in association with TD returned both non-significant (Bakker et al., 2012) and significant results (Greenbaum et al., 2012; Zai et al., 2018a). A meta-analysis of 324 patients with TD and 515 without TD indicated that HSPG2 rs2445142 G allele was significantly associated with TD (Zai et al., 2018a). Association between HSPG2 rs2445142 G allele and TD risk was also reported in a patient cohort of Jewish Israeli descent (Greenbaum et al., 2012).

Even though studied polymorphisms in DTNBP1 did not reach statistical significance, it should be pointed out that a haplotype comprised of rs2619539 G allele, rs875462 T allele, and rs $17470454 \mathrm{G}$ allele was associated with higher TD risk and a haplotype with rs760761 A, rs3213207 $\mathrm{T}$, and rs16876738 C alleles with TD severity (Maes et al., 2021). Mutations of DTNBP1 have also been associated with memory and 
TABLE 10 | Genetic variability of other genes and associations with TD.

\begin{tabular}{|c|c|c|c|}
\hline Genes & Genetic variations & Association & References \\
\hline \multirow[t]{3}{*}{$P I P 4 K 2 A$} & rs10828317 & Yes & Fedorenko et al. (2014) \\
\hline & rs746203 & No & Fedorenko et al. (2014) \\
\hline & rs8341 & No & Fedorenko et al. (2014) \\
\hline ESR1 & NA & Yes & Lai et al. (2002) \\
\hline \multirow[t]{3}{*}{$A p o E$} & ApoE $\varepsilon 2$ & No & Kimura et al. (2000) \\
\hline & ApoE $\varepsilon 3$ & No & Kimura et al. (2000) \\
\hline & ApoE $\varepsilon 4$ & No & Kimura et al. (2000) \\
\hline \multirow[t]{3}{*}{ PAWR } & rs7979987 & No & Kim et al. (2012) \\
\hline & rs4842318 & No & Kim et al. (2012) \\
\hline & rs17005769 & No & Kim et al. (2012) \\
\hline \multirow[t]{8}{*}{ DTNBP1 } & rs760761 & No & Maes et al. (2021) \\
\hline & rs3213207 & No & Maes et al. (2021) \\
\hline & rs16876738 & No & Maes et al. (2021) \\
\hline & rs2619539 & No & Maes et al. (2021) \\
\hline & rs875462 & No & Maes et al. (2021) \\
\hline & rs17470454 & No & Maes et al. (2021) \\
\hline & rs2619539, rs875462, rs17470454 & Yes - haplotype & Maes et al. (2021) \\
\hline & rs760761, rs3213207, rs16876738 & Yes - haplotype & Maes et al. (2021) \\
\hline \multirow[t]{4}{*}{ MTNR1A } & rs11721818 & No & Lai et al. (2011a) \\
\hline & rs2375801 & No & Lai et al. (2011a) \\
\hline & rs6553010 & No & Lai et al. (2011a) \\
\hline & rs11721818, rs2375801, rs6553010 & Yes - haplotype & Lai et al. (2011a) \\
\hline \multirow[t]{3}{*}{ MTNR1B } & rs4753426 & No & Lai et al. (2011a) \\
\hline & rs10830963 & No & Lai et al. (2011a) \\
\hline & rs3781637 & No & Lai et al. (2011a) \\
\hline \multirow[t]{7}{*}{ ADORA1 } & rs1874142 & No & Turčin et al. (2016) \\
\hline & rs10920568 & No & Turčin et al. (2016) \\
\hline & rs3766566 & No & Turčin et al. (2016) \\
\hline & rs3766560 & No & Turčin et al. (2016) \\
\hline & rs3753472 & No & Turčin et al. (2016) \\
\hline & rs3766553 & No & Turčin et al. (2016) \\
\hline & rs12744240 & No & Turčin et al. (2016) \\
\hline \multirow[t]{6}{*}{$A D O R A 2 A$} & rs35060421 & No & Ivanova et al. (2012a) \\
\hline & rs2298383 & No & Turčin et al. (2016) \\
\hline & rs17004921 & No & Turčin et al. (2016) \\
\hline & rs5751876 & No & Turčin et al. (2016) \\
\hline & rs35320474 & No & Turčin et al. (2016) \\
\hline & rs2236624 & No & Turčin et al. (2016) \\
\hline \multirow[t]{7}{*}{ ADORA3 } & rs3394 & No & Turčin et al. (2016) \\
\hline & rs3393 & No & Turčin et al. (2016) \\
\hline & rs2229155 & No & Turčin et al. (2016) \\
\hline & rs35511654 & No & Turčin et al. (2016) \\
\hline & rs1544223 & No & Turčin et al. (2016) \\
\hline & rs2298191 & No & Turčin et al. (2016) \\
\hline & rs3394, rs3393, rs2229155, rs35511654, rs1544223, rs2298191 & Yes - haplotype & Turčin et al. (2016) \\
\hline$A C E$ & insertion/deletion in the 16th intron & No & Segman et al. (2002b) \\
\hline \multirow[t]{8}{*}{$A K T 1$} & rs3730358 & No & Zai et al. (2008); Levchenko et al. (2019) \\
\hline & rs1130214 & No & Zai et al. (2008); Levchenko et al. (2019) \\
\hline & rs2498784 & No & Zai et al. (2008) \\
\hline & rs2494746 & No & Zai et al. (2008) \\
\hline & rs10149779 & No & Zai et al. (2008) \\
\hline & rs2494738 & No & Zai et al. (2008) \\
\hline & rs3803304 & No & Zai et al. (2008) \\
\hline & rs2494731 & No & Zai et al. (2008) \\
\hline \multirow[t]{8}{*}{ HSPG2 } & rs2445142 & Yes & Greenbaum et al. (2012); Zai et al. (2018a) \\
\hline & & No & Bakker et al. (2012) \\
\hline & rs2270697 & No & Bakker et al. (2012); Ivanova et al. (2012b) \\
\hline & rrs4738269 & No & Greenbaum et al. (2012) \\
\hline & rs2061051 & No & Greenbaum et al. (2012) \\
\hline & rs2124368 & No & Greenbaum et al. (2012) \\
\hline & rs6698486 & No & Bakker et al. (2012) \\
\hline & rs886292 & No & Greenbaum et al. (2012) \\
\hline RGS2 & rs4606 & No & Koning et al. (2012) \\
\hline $\mathrm{TPH}$ & rs1800532 & No & Segman et al. (2003) \\
\hline
\end{tabular}


TABLE 11 | Genome-wide association studies of TD.

\begin{tabular}{|c|c|c|c|c|}
\hline Outcome & Number of subjects & Ethnicity & Platform & References \\
\hline $\begin{array}{l}\text { Association between SLC6A11 rs4684742, } \\
\text { GABRB2 rs918528 and GABRA3 rs2061051, } \\
\text { and TD development }\end{array}$ & $\begin{array}{l}\text { GWAS: } 100 \text { (50 with TD) } \\
\text { replication cohort: } 174 \text { ( } 36 \\
\text { with TD) }\end{array}$ & Japanese & $\begin{array}{l}\text { Sentrix Human-1 Genotyping BeadChip } \\
\text { (lllumina) }(40,573 \text { SNPs in } 13,307 \text { genes) }\end{array}$ & $\begin{array}{l}\text { Inada et al. } \\
\text { (2008) }\end{array}$ \\
\hline $\begin{array}{l}\text { Association between HSPG2 rs2445142 } \\
\text { and TD }\end{array}$ & $\begin{array}{l}\text { GWAS: } 100 \text { (50 with TD), } \\
\text { replication cohort: } 172 \text { ( } 36 \\
\text { with TD) }\end{array}$ & Japanese & $\begin{array}{l}\text { Illumina Sentrix Human-1 Genotyping 109k } \\
\text { BeadChip }\end{array}$ & Syu et al. (2010) \\
\hline Association between GL/2 rs3943552 and TD & 327 (131 with TD) & $\begin{array}{l}\text { European American, } \\
\text { African American and } \\
\text { others }\end{array}$ & $\begin{array}{l}\text { Affymetrix } 500 \mathrm{~K}(500,568 \text { SNPs) and the } \\
\text { Perlegen custom } 164 \mathrm{~K} \text { chip }(164,871 \text { SNPs) }\end{array}$ & $\begin{array}{l}\text { Greenbaum } \\
\text { et al. (2010) }\end{array}$ \\
\hline $\begin{array}{l}\text { Association between rs } 7669317 \text { located in an } \\
\text { intergenic region and AIMS }\end{array}$ & 738 (NA with TD) & $\begin{array}{l}\text { European American, } \\
\text { African American and } \\
\text { others }\end{array}$ & $\begin{array}{l}\text { Affymetrix 500K chipset (Santa Clara, CA, } \\
\text { United States) and a Perlegen custom 164K } \\
\text { chip }\end{array}$ & $\begin{array}{l}\text { Aberg et al. } \\
(2010)\end{array}$ \\
\hline $\begin{array}{l}\text { Association between SNPs in HSPG2 and TD } \\
\text { pathophysiology }\end{array}$ & $\begin{array}{l}\text { GWAS: } 100 \text { (50 with TD), } \\
\text { replication cohort: } 172 \text { ( } 36 \\
\text { with TD) }\end{array}$ & Japanese & NA & $\begin{array}{l}\text { Arinami and } \\
\text { Inada (2011) }\end{array}$ \\
\hline $\begin{array}{l}\text { Significant association between DPP6 } \\
\text { rs6977820 and TD }\end{array}$ & $\begin{array}{l}122 \text { ( } 61 \text { with TD), } \\
\text { replication cohort: } 174 \text { (36 } \\
\text { with TD) }\end{array}$ & Japanese & Illumina HumanHapCNV370 BeadChip & $\begin{array}{l}\text { Tanaka et al. } \\
\text { (2013) }\end{array}$ \\
\hline $\begin{array}{l}\text { Association between GSE1 rs11639774, } \\
\text { TNFRSF1B rs499646, EPB41L2 rs6926250, } \\
\text { and CALCOCO1 rs4237808 and TD }\end{array}$ & 1406 (280 with TD) & $\begin{array}{l}\text { Han Chinese, } \\
\text { European, African } \\
\text { American }\end{array}$ & $\begin{array}{l}\text { Illumina } 1 \text { M Duo Beadchip, Affymetrix 500K "A" } \\
\text { chipset (Nsp and Sty chips), and Perlegen's } \\
\text { custom } 164 \mathrm{~K} \text { chip }\end{array}$ & Lim et al. (2021) \\
\hline
\end{tabular}

schizophrenia through the glutamate pathway (Fallgatter et al., 2010; Hashimoto et al., 2010; Strohmaier et al., 2010).

PIP4K2A is a member of the phosphatidylinositol-5phosphate 4-kinase family and mediates secretion, cell proliferation, differentiation, and motility (Rameh et al., 1997). It is associated with cancer (Sivakumaren et al., 2020) and it has also been examined for potential involvement in schizophrenia, but only a minor association was reported (Thiselton et al., 2010). PIP4K2A rs10828317, rs746203, and rs8341 have been investigated for potential association with TD in a cohort of 491 patients of Siberian origin, but only rs10828317 was associated with TD development (Fedorenko et al., 2014).

Melatonin transmembrane receptor is a G-protein, found in the brain, where it is involved in the circadian rhythm pathway (Ebisawa et al., 1999; Stauch et al., 2019). Individual polymorphisms in the genes of melatonin receptors $1 \mathrm{~A}$ (MTNR1A) and 1B (MTNR1B) were not associated with TD. However, the haplotype comprised of MTNR1A rs11721818 A, rs $2375801 \mathrm{~T}$, and rs6553010 $\mathrm{G}$ alleles had a protective effect against TD (Lai et al., 2011a).

Genetic variability of $A K T 1$ (Zai et al., 2008; Levchenko et al., 2019), ACE (Segman et al., 2002b), APOE (Kimura et al., 2000), PAWR (Kim et al., 2012), TPH (Segman et al., 2003) and RGS2 (Koning et al., 2012) was also examined for potential association with TD, but without statistically significant results. All of the studies are presented in this chaptercan be found in the Supplementary Table S2.

\section{GENOME-WIDE ASSOCIATION STUDIES OF TARDIVE DYSKINESIA}

Since 2008, seven GWAS had a goal of identifying the genetic biomarkers of TD development (Table 11). All of them were focused on patients with schizophrenia treated with antipsychotics, for whom the diagnosis and the TD were assessed according to DSM-IV and AIMS, respectively.

The first GWAS investigated 13,307 genes and 40,573 SNPs and was accompanied by a replication study. The cohort was comprised of 100 patients of whom 50 had TD, but no SNP was significantly associated with TD after Bonferroni correction. However, ELOVL3 rs10748816, BCOR rs6609051, TCP10L rs7281019, CBLC rs10419669, SLC38A1 rs1444590, EHF rs286925, TBCD rs3744165, RBM17 rs2274359, DLG5 rs1058198, ABCC8 rs886292, MAN1A2 rs2306444, EDIL3 rs13153252, ANXA13 rs4242345, SMYD3 rs6426327 polymorphisms showed some initial potential, so authors attempted to evaluate their significance in a replication cohort, which included 174 (36 with TD) Japanese patients. SLC6A11 rs4684742, GABRB2 rs918528, and GABRA3 rs2061051 were all statistically significant in both the GWAS and the replication study, indicating that the GABA receptor signaling pathway may be involved in TD pathophysiology (Inada et al., 2008). The involvement of the GABA receptor signaling pathway in TD pathophysiology was also highlighted in a canonical pathwaybased analysis within a GWAS published in 2010. The GWAS included 100 Japanese schizophrenia patients (50 with treatmentresistant TD) and the findings were validated in an independent cohort of 172 patients (36 with treatment-resistant TD), identifying an association between several polymorphisms in the HSPG2 gene and TD (Arinami and Inada 2011).

Association between TD and HSPG2 rs2445142 was observed in an independent GWAS that studied a cohort of 100 Japanese schizophrenia patients that included 50 patients with TD. The study also included a validation cohort of 172 patients (36 with TD), who were genotyped for the following promising polymorphisms: PLOD1 rs7529452, HSPG2 rs2445142, COL11A1 rs1934712, MAN1A2 rs2306444, TBX15 rs869807, 
DUSP10 rs6668395, SMYD3 rs6426327, EML4 rs4558632, ASB3 rs6714424, LRRTM4 rs2060279, BUB1 rs11694702, KCNH7 rs1873201, UBE2E3 rs11688866, STAC rs3749279, TBL1XR1 rs6443468, LOC285513 rs13115988, C9 rs700237, MGC33648 rs832582, EDIL3 rs13153252, FER rs6594324, FAM46A rs915125, CDC2L6 rs2691180, CITED2 rs9376506, FLJ39824 rs1832445, ZMIZ2 rs3735478, DPP6 rs1047053, SULF1 rs2583086, KCNB2 rs4738269, STARS rs2927111, ANGPT1 rs3019982, ANXA13 rs4242345, COL15A1 rs1413299, RBM17 rs2274359, PCDH15 rs1932596, DLG5 rs1058198, ELOVL3 rs10748816, GBF1 rs2246775, MGMT rs765934, ABCC8 rs886292, EHF rs286925, SPCS2 rs568758, NEU3 rs624786, SLC38A1 rs1444590, KIAA1906 rs1154664, LIG4 rs1924174, SEC10L1 rs1189827, ITPK1 rs11625123, VRK1 rs10140345, GABRG3 rs2061051, APBA2 rs3764211, PML rs1036673, DNAH9 rs3809729, FBXW10 rs4630608, ACACA rs2287352, FLJ13841 rs3744165, DLGAP1 rs474122, HMG20B rs12460403, NPHS1 rs437168, CBLC rs10419669, HAS1 rs8112223, C20orf26 rs2328500, TCP10L rs7281019, and LOC91464 rs2056965 (Syu et al., 2010). Except for rs2445142 HSPG2, no other genetic variants reached statistical significance.

The importance of DPP6 was pointed out in a GWAS conducted on a cohort of 122 patients with schizophrenia (61 with TD) and verified in an independent cohort of 174 patients (36 with TD). DPP6 rs6977820, located in the first intron of DPP6, was statistically significantly associated with TD in both GWAS and replication study. In addition, 50-weeks administration of haloperidol was associated with high DPP6 expression in the prefrontal, striatal, hippocampal, and ventricular midbrain regions of mice. In contrast, low gene expression was observed in the human postmortem prefrontal cortex of those carrying the risk allele. The authors concluded that the increased production of DPP6 might decrease dopamine release, which lowers dopamine sensitivity (Tanaka et al., 2013). DPP6 is a membrane protein and member of serine proteases, with an affinity for specific voltage-gated potassium channels, altering their expression. It is predominantly expressed in the brain and might be involved in neuronal plasticity and amyotrophic lateral sclerosis (Jerng et al., 2004). DPP6 protein can regulate the membrane trafficking of KV4 proteins and modify channel properties (Clark et al., 2008). Importantly, KV4 channels regulate the activity of dopaminergic neurons (Tanaka et al., 2013).

A GWAS that was performed on a cohort of 738 patients with schizophrenia within the CATIE study (Clinical Antipsychotic Trial of Intervention Effectiveness) should also be mentioned, even though it focused not solely on TD, but more broadly on movement disorders. A statistically significant association was recorded between rs7669317, AIMS scores, and probable TD. This polymorphism is located in the intergenic region of the chromosome $4 \mathrm{q} 24$, very close to PPA2 (Aberg et al., 2010).

An additional two-step study was performed on a cohort of 327 patients within the CATIE cohort, 131 of whom experienced TD. Authors conducted a GWAS using the genotype data from the CATIE study, followed by a validation study with the SNPs shown to be significant in the first stage. Among the 25 SNPs investigated and genotyped by Sequenom MassArray, GLI2 rs3943552 was significantly associated with TD (Greenbaum et al., 2010). GLI2 is a transcription factor involved in the sonic hedgehog signaling pathway, which was found to play an essential role in controlling voluntary motor movement through the differentiation of midbrain dopaminergic neurons (Abeliovich and Hammond 2007; Tolosa et al., 2020).

Lastly, the largest GWAS was published in 2021. The cohort of patients was comprised of 1406 patients (208 with TD) of Han Chinese, European and African American descent. To investigate the genetic variability of the potential underlying mechanisms and pathways of TD, they applied a robust and thorough bioinformatic analysis, including meta-analysis, functional annotation, eQTLs, transcriptome-wide finemapping, polygenic risk score analyses and multivariate logistic regression analyses. The study revealed the importance of three genomic loci on chromosomes 1, 6 and 12 and a novel locus on chromosome 16, highlighting the importance of TNFRSF1B, EPB41L2, CALCOCO1 and GSE1 genes (Lim et al., 2021). TNFRSF1B is a member of the tumor necrosis factor receptor superfamily and participates in the antiapoptotic signaling pathway. It is expressed in immune cells, highlighting the importance of immune system in TD pathogenesis (Lee and Kang 2011; Lanning et al., 2016; Lim et al., 2021). EPB41L2 is a membrane protein that was found to have a protective effect on motor activity. Published data suggest that its deficiency in mice convoy motor movement dysfunctions due to its involvement in cytoskeletal binding (Saitoh et al., 2017; Lim et al., 2021). CALCOCO1 was recently found to be involved in the autophagy of endoplasmic reticulum (Nthiga et al., 2020) and the transcriptional activation of target genes in the Wnt/ CTNNB1 pathway (Mizuta et al., 2014). GSE1 encodes a proline-rich protein with coiled-coil domains, named KIAA0182 and it is regulated by miR-489-5p. In breast cancer, GSE1 is overexpressed, while breast cancer cells' proliferation, migration and invasion are inhibited when silencing the gene (Chai et al., 2016). Similarly, GSE1 is overexpressed in gastric cancer cells treated with trastuzumab, while its deletion leads to reduced trastuzumab resistance of trastuzumab-resistant gastric cancer cells (Wang et al., 2021b).

\section{TRANSLATING PRE-CLINICAL AND CLINICAL FINDINGS TO CLINICAL PRACTICE: WHERE NEXT?}

This comprehensive review of the published findings of studies in experimental animal models and clinical studies focusing on the potential association between genetic variations and TD occurrence shows a rather significant discrepancy between genes and proteins investigated in preclinical and clinical settings.

However, we were able to identify eight genes that may be implicated in the molecular pathogenesis of TD based on the findings of the preclinical studies and which also reached statistical significance in at least one clinical study. However, 
the results of pharmacogenetic studies were often inconclusive or even conflicting.

Probably the most interesting entity involves the VMAT2, a transporter of the monoamine neurotransmitters from the cytosol into synaptic vesicles. The levels of VMAT2 were decreased in the experimental animals with VCM (Lévesque et al., 2017) and genetic variability of SLC18A2 was associated with TD in two different pharmacogenetic studies (Zai et al., 2013; Lu et al., 2018). One of the most promising potential treatments for TD are the VMAT2 inhibitors, such as valbenazine and deutetrabenazine, which were approved by the FDA in 2017 (Arya et al., 2019). The detection of functionally relevant SLC18A2 variants could allow identification of potential perturbations in VMAT2 function before the treatment initiation and would offer a window of opportunity to administer VMAT2 inhibitors along with the antipsychotic treatment to prevent TD development in the first place.

Furthermore, dopamine receptors 1 and 3 were also involved in the TD development in preclinical and at least one clinical study. It was shown that DRD1 binding is decreased in capuchin monkeys which developed TD upon haloperidol treatment (Mahmoudi et al., 2014). In addition, it was shown that the DRD1 rs4532 CC genotype is associated with increased TD risk. $D R D 1$ rs4532 is a promoter polymorphism, which means that it may affect gene expression, but the exact SNP function is not known yet (Lai et al., 2011b). Moreover, DRD3 binding was increased in the monkeys with TD (Mahmoudi et al., 2014). In line with this, the DRD3 rs6280 that increases the binding affinity of the receptor was associated with a higher chance of TD development (Steen et al., 1997; Basile et al., 1999; Segman et al., 1999, Segman et al., 2002a; Liao et al., 2001; Lerer et al., 2002; Woo et al., 2002; de Leon et al., 2005; Al Hadithy et al., 2009).

As a part of the serotonergic system, HTR2A was upregulated in the capuchin monkeys with $\mathrm{TD}$, treated with haloperidol (Lévesque et al., 2017). Along with that, three HTR2A SNPs were associated with TD development (Segman et al., 2001; Tan et al., 2001; Hsieh et al., 2011; Pozhidaev et al., 2020).

The levels of glutamate receptors GRIN2A and GRIN2B were also shown to be increased in capuchin monkeys with TD due to haloperidol treatment (Lévesque et al., 2017). Furthermore, several GRIN2A SNPs (Ivanova et al., 2012b; Ivanova et al., 2016b) and one GRIN2B SNP (Ivanova et al., 2012b) were associated with the occurrence of TD. The functionality of the GRIN2A and GRIN2B SNP is not well known. Nevertheless, they may present a promising biomarker for identifying patients with increased risk for TD development.

A critical pathway associated with TD development is also the defense against reactive oxygen species. Animal studies showed that the activity of SOD is decreased in TD affected animals, which probably explains elevated oxidative stress in TD (Patil et al., 2012; Nade et al., 2013; Thakur et al., 2015; Wang et al., 2015; Samad and Haleem 2017; Dhingra et al., 2018; Soung et al., 2018; Tsai et al., 2019; Wang et al., 2021a). The pharmacogenetic studies of candidate genes also identified a promising genetic biomarker of TD within this pathway, namely SOD2 rs4880 (Hori et al., 2000). This SNP decreases enzyme's activity and thus increases the risk for TD development and these observations agree with the results of the animal studies.

Lastly, CYP2D6 was shown to be decreased in the animals developing TD (Miksys et al., 2017), which agrees with the pharmacogenetic studies. The latter consistently reported that carriers of CYP2D6 with decreased metabolizing capacity had increased odds for TD development (Koola et al., 2014; Lu et al., 2020).

All the available published information regarding the impact of human genetic variations on drug response is compiled and publicly available from the Pharmacogenomics Knowledge Base (PharmGKB) (Relling and Klein 2011; Whirl-Carrillo et al., 2012, Whirl-Carrillo et al., 2021). The database provides clinically actionable gene-drug and genotype-phenotype associations and pharmacogenomic guidelines for a variety of drugs (https://www. pharmgkb.org/). In addition, it provides information about the significance of the drug-gene association, using the term "level of evidence (LOE)," which ranges from 1 to 4 . Level 1 A describes the strongest variant-drug association, for which there is either a clinical pharmacogenomic recommendation or an FDAapproved drug label annotation. On the other hand, LOE 4 refers to evidence that is insufficient to support associations between the genetic variant and the drug phenotype. Regarding TD, PharmGKB has three clinical annotations listing variant-antipsychotic combinations, all of them reaching $\mathrm{LOE}$ 3. This level of evidence indicates a low-level association, which might be supported either by one single study or several studies that failed to validate the association. According to PharmGKB clinical annotations, patients with the COMT rs4680 GG genotype, HTR2A rs6311 TT genotype, and DPP6 rs6977820 TT genotype, who are treated with antipsychotics, have a higher chance for TD development (https://www.pharmgkb.org/disease/PA447268/

clinicalAnnotation).

Based on the above, it is evident that despite the high number of clinical and preclinical studies conducted in $\mathrm{TD}$, the translation of the acquired knowledge to the everyday clinical practice is still lagging. More clinical studies with larger sample sizes are needed to validate the results and provide evidence for pharmacogenomic recommendations that can be implemented into the clinical practice.

\section{CONCLUSION}

Our comprehensive review showed that the preclinical and clinical studies helped to elucidate some molecular mechanisms implicated in TD development and suggested that genetic variability in these pathways may provide some promising biomarkers of TD. However, the clinical studies have failed to provide sufficient evidence for establishing pharmacogenomic recommendations that would support their implementation into psychiatric clinical practice. The studies that emerged from our literature review investigated $\mathrm{TD}$ in patients of diverse origins, which might explain the 
conflicting results. Moreover, the included cohorts' sizes were often small, which might explain the inability to replicate the findings in some cases. Additionally, in most of the studies, risk factors for TD, like demographics, health behavior, and clinical variables, have not been considered. Finally, the studies presented in this review indicate the contribution of a single gene to the development of TD, in contrast with the fundamentals of pharmacogenomics which focuses on the contribution of multiple genes and variants. Including cohorts with bigger sizes that are very well defined in terms of dose and drug duration, smoking status, alcohol or drug use, co-medication, comorbidities, and family history of psychiatric disorders in future studies will increase our understanding of the contribution of genetic factors to the emergence of TD and will lead to selecting the ideal treatment for each patient, aiming to provide a better quality of life for patients and their caregivers. Therefore, future studies integrating different approaches, such as metabolic, neurophysiological, and genetic, are needed to elucidate the potential interactions and support the development of a personalized approach for TD management and prevention.

\section{REFERENCES}

Abeliovich, A., and Hammond, R. (2007). Midbrain Dopamine Neuron Differentiation: Factors and Fates. Dev. Biol. 304, 447-454. doi:10.1016/ j.ydbio.2007.01.032

Aberg, K., Adkins, D. E., Bukszár, J., Webb, B. T., Caroff, S. N., Miller, D. D., et al. (2010). Genomewide Association Study of Movement-Related Adverse Antipsychotic Effects. Biol. Psychiatry 67, 279-282. doi:10.1016/ j.biopsych.2009.08.036

Al Hadithy, A. F., Ivanova, S. A., Pechlivanoglou, P., Semke, A., Fedorenko, O., Kornetova, E., et al. (2009). Tardive Dyskinesia and DRD3, HTR2A and HTR2C Gene Polymorphisms in Russian Psychiatric Inpatients from Siberia. Prog. Neuropsychopharmacol. Biol. Psychiatry 33, 475-481. doi:10.1016/j.pnpbp.2009.01.010

Alkelai, A., Greenbaum, L., Heinzen, E. L., Baugh, E. H., Teitelbaum, A., Zhu, X., et al. (2019). New Insights into Tardive Dyskinesia Genetics: Implementation of Whole-Exome Sequencing Approach. Prog. Neuropsychopharmacol. Biol. Psychiatry 94, 109659. doi:10.1016/j.pnpbp.2019.109659

American Psychiatric Association (2013). Diagnostic and Statistical Manual of Mental Disorders DSM-5. 5th edn. Arlington: American Psychiatric Publishing.

An, H. M., Tan, Y. L., Shi, J., Wang, Z. R., Li, J., Wang, Y. C., et al. (2013). Extract of Ginkgo Biloba Is Equivalent to Vitamin E in Attenuating and Preventing Vacuous Chewing Movements in a Rat Model of Tardive Dyskinesia. Behav. Pharmacol. 24, 610-616. doi:10.1097/ FBP.0b013e3283656d87

An, H. M., Tan, Y. L., Shi, J., Wang, Z. R., Li, J., Wang, Y. C., et al. (2016). Beneficial Effects of EGb761 and Vitamin E on Haloperidol-Induced Vacuous Chewing Movements in Rats: Possible Involvement of S100B Mechanisms. Behav. Brain Res. 297, 124-130. doi:10.1016/j.bbr.2015.10.004

Andreassen, O. A., MacEwan, T., Gulbrandsen, A. K., McCreadie, R. G., and Steen, V. M. (1997). Non-functional CYP2D6 Alleles and Risk for NeurolepticInduced Movement Disorders in Schizophrenic Patients. Psychopharmacology (Berl) 131, 174-179. doi:10.1007/s002130050281

Arias Horcajadas, F., Dávila Piriz, J. R., Parra González, A., Sánchez Romero, S., Sánchez-Morla, E., Ampuero Sánchez, I., et al. (2021). El Gen del receptor cannabinoide tipo 2 se asocia con la comorbilidad entre esquizofrenia y dependencia de cannabis y el gen de la enzima amidohidrolasa de ácidos grasos se asocia con la dependencia de cannabis en población española. Adicciones 0, 1587. doi:10.20882/adicciones.1587

\section{AUTHOR CONTRIBUTIONS}

EET and VD conceptualized the review. EET and SR performed literature search and prepared the first draft and the tables. All authors participated in writing and editing of the manuscript. All authors read and approved the final manuscript.

\section{FUNDING}

This work has received funding from the Slovenian Research Agency (ARRS Grant No. P1-0170). The results reflect only the authors' view. The Research Agency is not responsible for any use that may be made of the information this publication contains.

\section{SUPPLEMENTARY MATERIAL}

The Supplementary Material for this article can be found online at: https://www.frontiersin.org/articles/10.3389/fphar.2021.834129/ full\#supplementary-material

Arikawa-Hirasawa, E., Wilcox, W. R., Le, A. H., Silverman, N., Govindraj, P., Hassell, J. R., et al. (2001). Dyssegmental Dysplasia, Silverman-Handmaker Type, Is Caused by Functional Null Mutations of the Perlecan Gene. Nat. Genet. 27, 431-434. doi:10.1038/86941

Arikawa-Hirasawa, E., Le, A. H., Nishino, I., Nonaka, I., Ho, N. C., Francomano, C. A., et al. (2002). Structural and Functional Mutations of the Perlecan Gene Cause Schwartz-Jampel Syndrome, with Myotonic Myopathy and Chondrodysplasia. Am. J. Hum. Genet. 70, 1368-1375. doi:10.1086/340390

Arinami, T., and Inada, T. (2011). Genome-Wide Association Analyses for Neuroleptic-Induced Tardive Dyskinesia. Nihon Shinkei Seishin Yakurigaku Zasshi 31, 155-162.

Armstrong, M., Daly, A. K., Blennerhassett, R., Ferrier, N., and Idle, J. R. (1997). Antipsychotic Drug-Induced Movement Disorders in Schizophrenics in Relation to CYP2D6 Genotype. Br. J. Psychiatry 170, 23-26. doi:10.1192/ bjp.170.1.23

Arthur, H., Dahl, M. L., Siwers, B., and Sjöqvist, F. (1995). Polymorphic Drug Metabolism in Schizophrenic Patients with Tardive Dyskinesia. J. Clin. Psychopharmacol. 15, 211-216. doi:10.1097/00004714-199506000-00010

Arya, D., Khan, T., Margolius, A. J., and Fernandez, H. H. (2019). Tardive Dyskinesia: Treatment Update. Curr. Neurol. Neurosci. Rep. 19, 69. doi:10.1007/s11910-019-0976-1

Azorin, J. M., and Simon, N. (2019). Dopamine Receptor Partial Agonists for the Treatment of Bipolar Disorder. Drugs 79, 1657-1677. doi:10.1007/s40265-01901189-8

Bai, Y. M., Yu, S. C., and Lin, C. C. (2003). Risperidone for Severe Tardive Dyskinesia: A 12-Week Randomized, Double-Blind, Placebo-Controlled Study. J. Clin. Psychiatry 64, 1342-1348. doi:10.4088/JCP.v64n1110

Bakker, P. R., van Harten, P. N., and van Os, J. (2006). Antipsychotic-induced Tardive Dyskinesia and the Ser9Gly Polymorphism in the DRD3 Gene: a Meta Analysis. Schizophr Res. 83, 185-192. doi:10.1016/j.schres.2006.01.010

Bakker, P. R., van Harten, P. N., and van Os, J. (2008). Antipsychotic-induced Tardive Dyskinesia and Polymorphic Variations in COMT, DRD2, CYP1A2 and MnSOD Genes: a Meta-Analysis of Pharmacogenetic Interactions. Mol. Psychiatry 13, 544-556. doi:10.1038/sj.mp.4002142

Bakker, P. R., Al Hadithy, A. F., Amin, N., van Duijn, C. M., van Os, J., and van Harten, P. N. (2012). Antipsychotic-induced Movement Disorders in Long-Stay Psychiatric Patients and 45 Tag SNPs in 7 Candidate Genes: a Prospective Study. PLoS One 7, e50970. doi:10.1371/journal.pone.0050970

Basile, V. S., Masellis, M., Badri, F., Paterson, A. D., Meltzer, H. Y., Lieberman, J. A., et al. (1999). Association of the MscI Polymorphism of the Dopamine D3 
Receptor Gene with Tardive Dyskinesia in Schizophrenia. Neuropsychopharmacology 21, 17-27. doi:10.1016/S0893-133X(98)00114-6

Basile, V. S., Ozdemir, V., Masellis, M., Walker, M. L., Meltzer, H. Y., Lieberman, J. A., et al. (2000). A Functional Polymorphism of the Cytochrome P450 1A2 (CYP1A2) Gene: Association with Tardive Dyskinesia in Schizophrenia. Mol. Psychiatry 5, 410-417. doi:10.1038/sj.mp.4000736

Basile, V. S., Ozdemir, V., Masellis, M., Meltzer, H. Y., Lieberman, J. A., Potkin, S. G., et al. (2001). Lack of Association between serotonin-2A Receptor Gene (HTR2A) Polymorphisms and Tardive Dyskinesia in Schizophrenia. Mol. Psychiatry 6, 230-234. doi:10.1038/sj.mp.4000847

Bergman, H., Rathbone, J., Agarwal, V., and Soares-Weiser, K. (2018). Antipsychotic Reduction And/or Cessation and Antipsychotics as Specific Treatments for Tardive Dyskinesia. Cochrane Database Syst. Rev. 2, CD000459. doi:10.1002/14651858.CD000459.pub3

Bishnoi, M., and Boparai, R. K. (2012). An Animal Model to Study the Molecular Basis of Tardive Dyskinesia. Methods Mol. Biol. 829, 193-201. doi:10.1007/9781-61779-458-2_12

Blanchet, P. J., Parent, M. T., Rompré, P. H., and Lévesque, D. (2012). Relevance of Animal Models to Human Tardive Dyskinesia. Behav. Brain Funct. 8, 12. doi:10.1186/1744-9081-8-12

Boiko, A. S., Ivanova, S. A., Pozhidaev, I. V., Freidin, M. B., Osmanova, D. Z., Fedorenko, O. Y., et al. (2020). Pharmacogenetics of Tardive Dyskinesia in Schizophrenia: The Role of CHRM1 and CHRM2 Muscarinic Receptors. World J. Biol. Psychiatry 21, 72-77. doi:10.1080/15622975.2018.1548780

Boke, O., Gunes, S., Kara, N., Aker, S., Sahin, A. R., Basar, Y., et al. (2007). Association of Serotonin 2A Receptor and Lack of Association of CYP1A2 Gene Polymorphism with Tardive Dyskinesia in a Turkish Population. DNA Cel. Biol. 26, 527-531. doi:10.1089/dna.2007.0605

Bordia, T., McIntosh, J. M., and Quik, M. (2012). Nicotine Reduces AntipsychoticInduced Orofacial Dyskinesia in Rats. J. Pharmacol. Exp. Ther. 340, 612-619. doi:10.1124/jpet.111.189100

Bošković, M., Vovk, T., Saje, M., Goričar, K., Dolžan, V., Kores Plesničar, B., et al. (2013). Association of SOD2, GPX1, CAT, and TNF Genetic Polymorphisms with Oxidative Stress, Neurochemistry, Psychopathology, and Extrapyramidal Symptoms in Schizophrenia. Neurochem. Res. 38, 433-442. doi:10.1007/ s11064-012-0937-4

Brockmoller, J., Kirchheiner, J., Schmider, J., Walter, S., Sachse, C., Mulleroerlinghausen, B., et al. (2002). The Impact of the Polymorphism on Haloperidol Pharmacokinetics and on the Outcome of Haloperidol Treatment. Clin. Pharmacol. Ther. 72, 438-452. doi:10.1067/mcp.2002.127494

Busanello, A., Peroza, L. R., Wagner, C., Sudati, J. H., Pereira, R. P., Prestes, Ade. S., et al. (2012). Resveratrol Reduces Vacuous Chewing Movements Induced by Acute Treatment with Fluphenazine. Pharmacol. Biochem. Behav. 101, 307-310. doi:10.1016/j.pbb.2012.01.007

Busanello, A., Leal, C. Q., Peroza, L. R., Röpke, J., de Moraes Reis, E., de Freitas, C. M., et al. (2017). Resveratrol Protects against Vacuous Chewing Movements Induced by Chronic Treatment with Fluphenazine. Neurochem. Res. 42, 3033-3040. doi:10.1007/s11064-017-2335-4

Carbon, M., Kane, J. M., Leucht, S., and Correll, C. U. (2018). Tardive Dyskinesia Risk with First- and Second-Generation Antipsychotics in Comparative Randomized Controlled Trials: a Meta-Analysis. World Psychiatry 17, 330-340. doi:10.1002/wps.20579

Caroff, S. N., Leong, S. H., Roberts, C. B., Berkowitz, R. M., and Campbell, E. C. (2020). Correlates of the Abnormal Involuntary Movement Scale in Veterans with Tardive Dyskinesia. J. Clin. Psychopharmacol. 40, 373-380. doi:10.1097/ JCP.0000000000001229

Ceretta, A. P. C., de Freitas, C. M., Schaffer, L. F., Reinheimer, J. B., Dotto, M. M., de Moraes Reis, E., et al. (2018). Gabapentin Reduces Haloperidol-Induced Vacuous Chewing Movements in Mice. Pharmacol. Biochem. Behav. 166, 21-26. doi:10.1016/j.pbb.2018.01.003

Chai, P., Tian, J., Zhao, D., Zhang, H., Cui, J., Ding, K., et al. (2016). GSE1 Negative Regulation by miR-489-5p Promotes Breast Cancer Cell Proliferation and Invasion. Biochem. Biophys. Res. Commun. 471, 123-128. doi:10.1016/ j.bbrc.2016.01.168

Chen, C. H., Wei, F. C., Koong, F. J., and Hsiao, K. J. (1997). Association of TaqI A Polymorphism of Dopamine D2 Receptor Gene and Tardive Dyskinesia in Schizophrenia. Biol. Psychiatry 41, 827-829. doi:10.1016/S0006-3223(96) 00543-4
Chen, C. N., Chang, K. C., Wang, M. H., Tseng, H. C., and Soung, H. S. (2018). Protective Effect of L-Theanine on Haloperidol-Induced Orofacial. Chin. J. Physiol. 61, 35-41. doi:10.4077/CJP.2018.BAG529

Chong, S. A., Tan, E. C., Tan, C. H., Mahendren, R., Tay, A. H., and Chua, H. C. (2000). Tardive Dyskinesia Is Not Associated with the Serotonin Gene Polymorphism (5-HTTLPR) in Chinese. Am. J. Med. Genet. 96, 712-715. doi:10.1002/1096-8628(20001204)96:6<712:aid-ajmg2>3.0.co;2-u

Chong, S. A., Tan, E. C., Tan, C. H., Mythilyand Chan, Y. H. (2003a). Polymorphisms of Dopamine Receptors and Tardive Dyskinesia Among Chinese Patients with Schizophrenia. Am. J. Med. Genet. B Neuropsychiatr. Genet. 116B, 51-54. doi:10.1002/ajmg.b.10004

Chong, S. A., Tan, E. C., Tan, C. H., and Mythily, S. (2003b). Smoking and Tardive Dyskinesia: Lack of Involvement of the CYP1A2 Gene. J. Psychiatry Neurosci. $28,185-189$.

Clark, B. D., Kwon, E., Maffie, J., Jeong, H. Y., Nadal, M., Strop, P., et al. (2008). DPP6 Localization in Brain Supports Function as a Kv4 Channel Associated Protein. Front. Mol. Neurosci. 1, 8. doi:10.3389/neuro.02.008.2008

Crisafulli, C., Drago, A., Sidoti, A., and Serretti, A. (2013). A Genetic Dissection of Antipsychotic Induced Movement Disorders. Curr. Med. Chem. 20, 312-330. doi:10.2174/0929867311320030002

Crowley, J. J., Lipsky, R. H., Lucki, I., and Berrettini, W. H. (2008). Variation in the Genes Encoding Vesicular Monoamine Transporter 2 and Beta-1 Adrenergic Receptor and Antidepressant Treatment Outcome. Psychiatr. Genet. 18, 248-251. doi:10.1097/YPG.0b013e3283052ff7

Crowley, J. J., Kim, Y., Szatkiewicz, J. P., Pratt, A. L., Quackenbush, C. R., Adkins, D. E., et al. (2012). Genome-wide Association Mapping of Loci for Antipsychotic-Induced Extrapyramidal Symptoms in Mice. Mamm. Genome 23, 322-335. doi:10.1007/s00335-011-9385-8

Datta, S., Jamwal, S., Deshmukh, R., and Kumar, P. (2016). Beneficial Effects of Lycopene against Haloperidol Induced Orofacial Dyskinesia in Rats: Possible Neurotransmitters and Neuroinflammation Modulation. Eur. J. Pharmacol. 771, 229-235. doi:10.1016/j.ejphar.2015.12.032

de Leon, J., Susce, M. T., Pan, R. M., Koch, W. H., and Wedlund, P. J. (2005). Polymorphic Variations in GSTM1, GSTT1, PgP, CYP2D6, CYP3A5, and Dopamine D2 and D3 Receptors and Their Association with Tardive Dyskinesia in Severe Mental Illness. J. Clin. Psychopharmacol. 25, 448-456. doi:10.1097/01.jcp.0000177546.34799.af

De Luca, V., Souza, R. P., Viggiano, E., Zai, C. C., Shinkai, T., Lieberman, J. A., et al. (2009). MDR1 Gene in Tardive Dyskinesia Scale Scores: Comparison of Strategies for Quantitative Trait Haplotype Analysis. Schizophr. Res. 110, 200-201. doi:10.1016/j.schres.2009.01.021

de Oliveira, G. V., Gomes, P. X., de Araújo, F. Y., Vasconcelos, S. M., Júnior, H. V., de Sousa, F. C., et al. (2013). Prevention of Haloperidol-Induced Alterations in Brain Acetylcholinesterase Activity by Vitamins B Co-Administration in a Rodent Model of Tardive Dyskinesia. Metab. Brain Dis. 28, 53-59. doi:10.1007/ s11011-012-9345-3

Deb, I., Chakraborty, J., Gangopadhyay, P. K., Choudhury, S. R., and Das, S. (2010). Single-nucleotide Polymorphism (A118G) in Exon 1 of OPRM1 Gene Causes Alteration in Downstream Signaling by $\mathrm{Mu}$-Opioid Receptor and May Contribute to the Genetic Risk for Addiction. J. Neurochem. 112, 486-496. doi:10.1111/j.1471-4159.2009.06472.x

Dennis, J. A., Gittner, L. S., Payne, J. D., and Nugent, K. (2020). Characteristics of U.S. Adults Taking Prescription Antipsychotic Medications, National Health and Nutrition Examination Survey 2013-2018. BMC Psychiatry 20, 483. doi:10.1186/s12888-020-02895-4

Dhingra, D., Goswami, S., and Gahalain, N. (2018). Protective Effect of Hesperetin against Haloperidol-Induced Orofacial Dyskinesia and Catalepsy in Rats. Nutr. Neurosci. 21, 667-675. doi:10.1080/1028415X.2017.1338549

Dick, D. M., Aliev, F., Kramer, J., Wang, J. C., Hinrichs, A., Bertelsen, S., et al. (2007). Association of CHRM2 with IQ: Converging Evidence for a Gene Influencing Intelligence. Behav. Genet. 37, 265-272. doi:10.1007/s10519-006-9131-2

Dolzan, V., Plesnicar, B. K., Serretti, A., Mandelli, L., Zalar, B., Koprivsek, J., et al. (2007). Polymorphisms in Dopamine Receptor DRD1 and DRD2 Genes and Psychopathological and Extrapyramidal Symptoms in Patients on Long-Term Antipsychotic Treatment. Am. J. Med. Genet. B Neuropsychiatr. Genet. 144B, 809-815. doi:10.1002/ajmg.b.30544

Ebisawa, T., Kajimura, N., Uchiyama, M., Katoh, M., Sekimoto, M., Watanabe, T., et al. (1999). Alleic Variants of Human Melatonin 1a Receptor: Function and 
Prevalence in Subjects with Circadian Rhythm Sleep Disorders. Biochem. Biophys. Res. Commun. 262, 832-837. doi:10.1006/bbrc.1999.1308

Ellingrod, V. L., Schultz, S. K., and Arndt, S. (2002). Abnormal Movements and Tardive Dyskinesia in Smokers and Nonsmokers with Schizophrenia Genotyped for Cytochrome P450 2D6. Pharmacotherapy 22, 1416-1419. doi:10.1592/phco.22.16.1416.33700

Endele, S., Rosenberger, G., Geider, K., Popp, B., Tamer, C., Stefanova, I., et al. (2010). Mutations in GRIN2A and GRIN2B Encoding Regulatory Subunits of NMDA Receptors Cause Variable Neurodevelopmental Phenotypes. Nat. Genet. 42, 1021-1026. doi:10.1038/ng.677

Fallgatter, A. J., Ehlis, A. C., Herrmann, M. J., Hohoff, C., Reif, A., Freitag, C. M., et al. (2010). DTNBP1 (Dysbindin) Gene Variants Modulate Prefrontal Brain Function in Schizophrenic Patients-Ssupport for the Glutamate Hypothesis of Schizophrenias. Genes Brain Behav. 9, 489-497. doi:10.1111/j.1601183X.2010.00574.X

Fan, H., Zhang, F., Xu, Y., Huang, X., Sun, G., Song, Y., et al. (2010). An Association Study of DRD2 Gene Polymorphisms with Schizophrenia in a Chinese Han Population. Neurosci. Lett. 477, 53-56. doi:10.1016/j.neulet.2009.11.017

Fedorenko, O. Y., Loonen, A. J., Lang, F., Toshchakova, V. A., Boyarko, E. G., Semke, A. V., et al. (2014). Association Study Indicates a Protective Role of Phosphatidylinositol-4-Phosphate-5-Kinase against Tardive Dyskinesia. Int. J. Neuropsychopharmacol. 18, pyu098. doi:10.1093/ijnp/pyu098

Fu, Y., Fan, C. H., Deng, H. H., Hu, S. H., Lv, D. P., Li, L. H., et al. (2006). Association of CYP2D6 and CYP1A2 Gene Polymorphism with Tardive Dyskinesia in Chinese Schizophrenic Patients. Acta Pharmacol. Sin 27, 328-332. doi:10.1111/j.1745-7254.2006.00279.x

Gaitonde, E. J., Morris, A., Sivagnanasundaram, S., McKenna, P. J., Hunt, D. M., and Mollon, J. D. (1996). Assessment of Association of D3 Dopamine Receptor MscI Polymorphism with Schizophrenia: Analysis of Symptom Ratings, Family History, Age at Onset, and Movement Disorders. Am. J. Med. Genet. 67, $455-458$.

doi:10.1002/(SICI)1096-8628(19960920)67:5<455:AIDAJMG3>3.0.CO;2-J

Garcia-Barceló, M. M., Lam, L. C., Ungvari, G. S., Lam, V. K., and Tang, W. K. (2001). Dopamine D3 Receptor Gene and Tardive Dyskinesia in Chinese Schizophrenic Patients. J. Neural Transm. (Vienna) 108, 671-677. doi:10.1007/s007020170044

Gerlach, J., Koppelhus, P., Helweg, E., and Monrad, A. (1974). Clozapine and Haloperidol in a Single-Blind Cross-Over Trial: Therapeutic and Biochemical Aspects in the Treatment of Schizophrenia. Acta Psychiatr. Scand. 50, 410-424. doi:10.1111/j.1600-0447.1974.tb09706.x

Goode-Romero, G., Winnberg, U., Domínguez, L., Ibarra, I. A., Vargas, R., Winnberg, E., et al. (2020). New Information of Dopaminergic Agents Based on Quantum Chemistry Calculations. Sci. Rep. 10, 21581. doi:10.1038/s41598-020-78446-4

Gopisankar, M. G. (2017). CYP2D6 Pharmacogenomics. Egypt. J. Med. Hum. Genet. 18, 309-313. doi:10.1016/j.ejmhg.2017.03.001

Greenbaum, L., Alkelai, A., Rigbi, A., Kohn, Y., and Lerer, B. (2010). Evidence for Association of the GLI2 Gene with Tardive Dyskinesia in Patients with Chronic Schizophrenia. Mov Disord. 25, 2809-2817. doi:10.1002/mds.23377

Greenbaum, L., Alkelai, A., Zozulinsky, P., Kohn, Y., and Lerer, B. (2012). Support for Association of HSPG2 with Tardive Dyskinesia in Caucasian Populations. Pharmacogenomics J. 12, 513-520. doi:10.1038/tpj.2011.32

Grossman, I., Sullivan, P. F., Walley, N., Liu, Y., Dawson, J. R., Gumbs, C., et al. (2008). Genetic Determinants of Variable Metabolism Have Little Impact on the Clinical Use of Leading Antipsychotics in the CATIE Study. Genet. Med. 10, 720-729. doi:10.1097/GIM.0b013e3181863239

Grover, S., Kumar, P., Singh, K., Vikram, V., and Budhiraja, R. D. (2013). Possible Beneficial Effect of Peroxisome Proliferator-Activated Receptor (PPAR)-- $\alpha$ and $\gamma$ Agonist against a Rat Model of Oral Dyskinesia. Pharmacol. Biochem. Behav. 111, 17-23. doi:10.1016/j.pbb.2013.08.001

Guy, W. (1976). ECDEU Assessment Manual for Psychopharmacology: Revised (DHEW Publication No. ADM 76-338). Rockville, MD: US Department of Health, Education and WelfarePublic Heal Serv.

Hashimoto, R., Noguchi, H., Hori, H., Nakabayashi, T., Suzuki, T., Iwata, N., et al. (2010). A Genetic Variation in the Dysbindin Gene (DTNBP1) Is Associated with Memory Performance in Healthy Controls. World J. Biol. Psychiatry 11, 431-438. doi:10.1080/15622970902736503
Hauser, R. A., and Truong, D. (2018). Tardive Dyskinesia: Out of the Shadows. J. Neurol. Sci. 389, 1-3. doi:10.1016/j.jns.2018.02.009

Herken, H., Erdal, M. E., Böke, O., and Savaş, H. A. (2003). Tardive Dyskinesia Is Not Associated with the Polymorphisms of 5-HT2A Receptor Gene, Serotonin Transporter Gene and Catechol-O-Methyltransferase Gene. Eur. Psychiatry 18, 77-81. doi:10.1016/s0924-9338(03)00005-1

Hernandez, G., Mahmoudi, S., Cyr, M., Diaz, J., Blanchet, P. J., and Lévesque, D. (2019). Tardive Dyskinesia Is Associated with Altered Putamen Akt/GSK-3 $\beta$ Signaling in Nonhuman Primates. Mov Disord. 34, 717-726. doi:10.1002/ mds. 27630

Hitzeroth, A., Niehaus, D. J., Koen, L., Botes, W. C., Deleuze, J. F., and Warnich, L. (2007). Association between the MnSOD Ala-9Val Polymorphism and Development of Schizophrenia and Abnormal Involuntary Movements in the Xhosa Population. Prog. Neuropsychopharmacol. Biol. Psychiatry 31, 664-672. doi:10.1016/j.pnpbp.2006.12.019

Hori, H., Ohmori, O., Shinkai, T., Kojima, H., Okano, C., Suzuki, T., et al. (2000). Manganese Superoxide Dismutase Gene Polymorphism and Schizophrenia: Relation to Tardive Dyskinesia. Neuropsychopharmacology 23, 170-177. doi:10.1016/S0893-133X(99)00156-6

Hori, H., Ohmori, O., Shinkai, T., Kojima, H., and Nakamura, J. (2001). Association between Three Functional Polymorphisms of Dopamine D2 Receptor Gene and Tardive Dyskinesia in Schizophrenia. Am. J. Med. Genet. 105, 774-778. doi:10.1002/ajmg.10045

Hsieh, C. J., Chen, Y. C., Lai, M. S., Hong, C. J., and Chien, K. L. (2011). Genetic Variability in Serotonin Receptor and Transporter Genes May Influence Risk for Tardive Dyskinesia in Chronic Schizophrenia. Psychiatry Res. 188, 175-176. doi:10.1016/j.psychres.2010.10.006

Hua, T., Vemuri, K., Pu, M., Qu, L., Han, G. W., Wu, Y., et al. (2016). Crystal Structure of the Human Cannabinoid Receptor CB1. Cell 167, 750-762.e14. doi:10.1016/j.cell.2016.10.004

Hui, L., Han, M., Huang, X. F., Ye, M. J., Zheng, K., He, J. C., et al. (2015). Possible Association between DBH 19 Bp Insertion/deletion Polymorphism and Clinical Symptoms in Schizophrenia with Tardive Dyskinesia. J. Neural Transm. (Vienna) 122, 907-914. doi:10.1007/s00702-014-1327-7

Hui, L., Han, M., Yin, G. Z., Zhang, Y., Huang, X. F., Qian, Z. K., et al. (2017). Association between DBH 19bp Insertion/deletion Polymorphism and Cognition in Schizophrenia with and without Tardive Dyskinesia. Schizophr Res. 182, 104-109. doi:10.1016/j.schres.2016.10.028

Inada, T., Senoo, H., Iijima, Y., Yamauchi, T., and Yagi, G. (2003). Cytochrome P450 II D6 Gene Polymorphisms and the Neuroleptic-Induced Extrapyramidal Symptoms in Japanese Schizophrenic Patients. Psychiatr. Genet. 13, 163-168. doi:10.1097/00041444-200309000-00005

Inada, T., Koga, M., Ishiguro, H., Horiuchi, Y., Syu, A., Yoshio, T., et al. (2008). Pathway-based Association Analysis of Genome-wide Screening Data Suggest that Genes Associated with the Gamma-Aminobutyric Acid Receptor Signaling Pathway Are Involved in Neuroleptic-Induced, Treatment-Resistant Tardive Dyskinesia. Pharmacogenet. Genomics 18, 317-323. doi:10.1097/ FPC.0b013e3282f70492

Islam, F., Men, X., Yoshida, K., Zai, C. C., and Müller, D. J. (2021). Pharmacogenetics-Guided Advances in Antipsychotic Treatment. Clin. Pharmacol. Ther. 110, 582-588. doi:10.1002/cpt.2339

Ivanova, S. A., Al Hadithy, A. F., Brazovskaya, N., Semke, A., Wilffert, B., Fedorenko, O., et al. (2012a). No Involvement of the Adenosine A2A Receptor in Tardive Dyskinesia in Russian Psychiatric Inpatients from Siberia. Hum. Psychopharmacol. 27, 334-337. doi:10.1002/hup.2226

Ivanova, S. A., Loonen, A. J., Pechlivanoglou, P., Freidin, M. B., Al Hadithy, A. F., Rudikov, E. V., et al. (2012b). NMDA Receptor Genotypes Associated with the Vulnerability to Develop Dyskinesia. Transl Psychiatry 2, e67. doi:10.1038/ tp.2011.66

Ivanova, S. A., Geers, L. M., Al Hadithy, A. F., Pechlivanoglou, P., Semke, A. V., Vyalova, N. M., et al. (2014). Dehydroepiandrosterone Sulphate as a Putative Protective Factor against Tardive Dyskinesia. Prog. Neuropsychopharmacol. Biol. Psychiatry 50, 172-177. doi:10.1016/j.pnpbp.2013.12.015

Ivanova, S. A., Toshchakova, V. A., Filipenko, M. L., Fedorenko, O. Y., Boyarko, E. G., Boiko, A. S., et al. (2015). Cytochrome P450 1A2 Co-determines Neuroleptic Load and May Diminish Tardive Dyskinesia by Increased Inducibility. World J. Biol. Psychiatry 16, 200-205. doi:10.3109/15622975.2014.995222 
Ivanova, S. A., Filipenko, M. L., Vyalova, N. M., Voronina, E. N., Pozhidaev, I. V., Osmanova, D. Z., et al. (2016a). CYP1A2 and CYP2D6 Gene Polymorphisms in Schizophrenic Patients with Neuroleptic Drug-Induced Side Effects. Bull. Exp. Biol. Med. 160, 687-690. doi:10.1007/s10517-016-3250-4

Ivanova, S. A., Loonen, A. J., Bakker, P. R., Freidin, M. B., Ter Woerds, N. J., Al Hadithy, A. F., et al. (2016b). Likelihood of Mechanistic Roles for Dopaminergic, Serotonergic and Glutamatergic Receptors in Tardive Dyskinesia: A Comparison of Genetic Variants in Two Independent Patient Populations. SAGE Open Med. 4, 2050312116643673. doi:10.1177/ 2050312116643673

Jaanson, P., Marandi, T., Kiivet, R. A., Vasar, V., Vään, S., Svensson, J. O., et al. (2002). Maintenance Therapy with Zuclopenthixol Decanoate: Associations between Plasma Concentrations, Neurological Side Effects and CYP2D6 Genotype. Psychopharmacology (Berl) 162, 67-73. doi:10.1007/s00213-0021059-5

James, S. L., Abate, D., Abate, K. H., Abay, S. M., Abbafati, C., Abbasi, N., et al. (2018). Global, Regional, and National Incidence, Prevalence, and Years Lived with Disability for 354 Diseases and Injuries for 195 Countries and Territories, 1990-2017: a Systematic Analysis for the Global Burden of Disease Study 2017. Lancet 392, 1789-1858. doi:10.1016/S0140-6736(18)32279-7

Jeanneteau, F., Funalot, B., Jankovic, J., Deng, H., Lagarde, J. P., Lucotte, G., et al. (2006). A Functional Variant of the Dopamine D3 Receptor Is Associated with Risk and Age-At-Onset of Essential Tremor. Proc. Natl. Acad. Sci. U S A. 103, 10753-10758. doi:10.1073/pnas.0508189103

Jerng, H. H., Qian, Y., and Pfaffinger, P. J. (2004). Modulation of Kv4.2 Channel Expression and Gating by Dipeptidyl Peptidase 10 (DPP10). Biophys. J. 87, 2380-2396. doi:10.1529/biophysj.104.042358

Kaiser, R., Tremblay, P. B., Klufmöller, F., Roots, I., and Brockmöller, J. (2002). Relationship between Adverse Effects of Antipsychotic Treatment and Dopamine $\mathrm{D}(2)$ Receptor Polymorphisms in Patients with Schizophrenia. Mol. Psychiatry 7, 695-705. doi:10.1038/sj.mp.4001054

Kajero, J. A., Seedat, S., Ohaeri, J., Akindele, A., and Aina, O. (2020). Investigation of the Effects of Cannabidiol on Vacuous Chewing Movements, Locomotion, Oxidative Stress and Blood Glucose in Rats Treated with Oral Haloperidol. World J. Biol. Psychiatry 21, 612-626. doi:10.1080/15622975.2020.1752934

Kang, S. G., Lee, H. J., Yoon, H. K., Cho, S. N., Park, Y. M., and Kim, L. (2013). There Is No Evidence for an Association between the Serotonin Receptor 3A Gene C178T Polymorphism and Tardive Dyskinesia in Korean Schizophrenia Patients. Nord J. Psychiatry 67, 214-218. doi:10.3109/08039488.2012.732114

Kapitany, T., Meszaros, K., Lenzinger, E., Schindler, S. D., Barnas, C., Fuchs, K., et al. (1998). Genetic Polymorphisms for Drug Metabolism (CYP2D6) and Tardive Dyskinesia in Schizophrenia. Schizophr Res. 32, 101-106. doi:10.1016/ s0920-9964(98)00038-3

Kazamatsuri, H., Chien, C., and Cole, J. O. (1972). Treatment of Tardive Dyskinesia. II. Short-Term Efficacy of Dopamine-Blocking Agents Haloperidol and Thiopropazate. Arch. Gen. Psychiatry 27, 100-103. doi:10.1001/archpsyc.1972.01750250086012

Kazamatsuri, H., Chien, C. P., and Cole, J. O. (1973). Long-term Treatment of Tardive Dyskinesia with Haloperidol and Tetrabenazine. Am. J. Psychiatry 130, 479-483. doi:10.1176/ajp.130.4.479

Keepers, G. A., Fochtmann, L. J., Anzia, J. M., Benjamin, S., Lyness, J. M., Mojtabai, R., et al. (2020). The American Psychiatric Association Practice Guideline for the Treatment of Patients with Schizophrenia. Am. J. Psychiatry 177, 868-872. doi:10.1176/appi.ajp.2020.177901

Khan, M. M., Xiao, J., Hollingsworth, T. J., Patel, D., Selley, D. E., Ring, T. L., et al. (2019). Gnal Haploinsufficiency Causes Genomic Instability and Increased Sensitivity to Haloperidol. Exp. Neurol. 318, 61-70. doi:10.1016/ j.expneurol.2019.04.014

Kim, I. S., Yoon, H. K., Kang, S. G., Park, Y. M., Kim, Y. K., Kim, S. H., et al. (2012). No Association between PAWR Gene Polymorphisms and Tardive Dyskinesia in Schizophrenia Patients. Psychiatry Investig. 9, 191-194. doi:10.4306/ pi.2012.9.2.191

Kimura, T., Shono, M., Yokota, S., Ishizuka, K., Watanabe, M., Takamatsu, J., et al. (2000). Apolipoprotein E Epsilon4 and Tardive Dyskinesia in a Japanese Population. J. Psychiatr. Res. 34, 329-332. doi:10.1016/s00223956(00)00023-6

Klein, C., Brin, M. F., Kramer, P., Sena-Esteves, M., de Leon, D., Doheny, D., et al. (1999). Association of a Missense Change in the D2 Dopamine Receptor with
Myoclonus Dystonia. Proc. Natl. Acad. Sci. U S A. 96, 5173-5176. doi:10.1073/ pnas.96.9.5173

Koning, J. P., Vehof, J., Burger, H., Wilffert, B., Al Hadithy, A., Alizadeh, B., et al. (2012). Association of Two DRD2 Gene Polymorphisms with Acute and Tardive Antipsychotic-Induced Movement Disorders in Young Caucasian Patients. Psychopharmacology (Berl) 219, 727-736. doi:10.1007/s00213-0112394-1

Koola, M. M., Tsapakis, E. M., Wright, P., Smith, S., Kerwin Rip, R. W., Nugent, K. L., et al. (2014). Association of Tardive Dyskinesia with Variation in CYP2D6: Is There a Role for Active Metabolites? J. Psychopharmacol. 28, 665-670. doi:10.1177/0269881114523861

Korsgaard, S., Noring, U., and Gerlach, J. (1984). Fluperlapine in Tardive Dyskinesia and Parkinsonism. Psychopharmacology (Berl) 84, 76-79. doi:10.1007/BF00432029

Kulkarni, S. K., and Dhir, A. (2011). Animal Models of Tardive Dyskinesia. Int. Rev. Neurobiol. 98, 265-287. doi:10.1016/B978-0-12-381328-2.00011-0

Kurian, M. A., Zhen, J., Cheng, S. Y., Li, Y., Mordekar, S. R., Jardine, P., et al. (2009). Homozygous Loss-Of-Function Mutations in the Gene Encoding the Dopamine Transporter Are Associated with Infantile ParkinsonismDystonia. J. Clin. Invest. 119, 1595-1603. doi:10.1172/JCI39060

Kurian, M. A., Gissen, P., Smith, M., Heales, S., and Clayton, P. T. (2011). The Monoamine Neurotransmitter Disorders: an Expanding Range of Neurological Syndromes. Lancet Neurol. 10, 721-733. doi:10.1016/S1474-4422(11)70141-7

Lai, I. C., Liao, D. L., Bai, Y. M., Lin, C. C., Yu, S. C., Chen, J. Y., et al. (2002). Association Study of the Estrogen Receptor Polymorphisms with Tardive Dyskinesia in Schizophrenia. Neuropsychobiology 46, 173-175. doi:10.1159/ 000067808

Lai, I. C., Wang, Y. C., Lin, C. C., Bai, Y. M., Liao, D. L., Yu, S. C., et al. (2005). Negative Association between Catechol-O-Methyltransferase (COMT) Gene Val158Met Polymorphism and Persistent Tardive Dyskinesia in Schizophrenia. J. Neural Transm. (Vienna) 112, 1107-1113. doi:10.1007/s00702-004-0252-6

Lai, I. C., Chen, M. L., Wang, Y. C., Chen, J. Y., Liao, D. L., Bai, Y. M., et al. (2011a). Analysis of Genetic Variations in the Human Melatonin Receptor (MTNR1A, MTNR1B) Genes and Antipsychotics-Induced Tardive Dyskinesia in Schizophrenia. World J. Biol. Psychiatry 12, 143-148. doi:10.3109/ 15622975.2010.496870

Lai, I. C., Mo, G. H., Chen, M. L., Wang, Y. C., Chen, J. Y., Liao, D. L., et al. (2011b). Analysis of Genetic Variations in the Dopamine D1 Receptor (DRD1) Gene and Antipsychotics-Induced Tardive Dyskinesia in Schizophrenia. Eur. J. Clin. Pharmacol. 67, 383-388. doi:10.1007/s00228-010-0967-2

Lam, L. C., Garcia-Barcelo, M. M., Ungvari, G. S., Tang, W. K., Lam, V. K., Kwong, S. L., et al. (2001). Cytochrome P450 2D6 Genotyping and Association with Tardive Dyskinesia in Chinese Schizophrenic Patients. Pharmacopsychiatry 34, 238-241. doi:10.1055/s-2001-18035

Lanning, R. K., Zai, C. C., and Müller, D. J. (2016). Pharmacogenetics of Tardive Dyskinesia: an Updated Review of the Literature. Pharmacogenomics 17, 1339-1351. doi:10.2217/pgs.16.26

Lanning, R., Lett, T. A., Tiwari, A. K., Brandl, E. J., de Luca, V., Voineskos, A. N., et al. (2017). Association Study between the Neurexin-1 Gene and Tardive Dyskinesia. Hum. Psychopharmacol. 32. doi:10.1002/hup.2568

Lévesque, C., Hernandez, G., Mahmoudi, S., Calon, F., Gasparini, F., Gomezmancilla, B., et al. (2017). Deficient Striatal Adaptation in Aminergic and Glutamatergic Neurotransmission Is Associated with Tardive Dyskinesia in Non-human Primates Exposed to Antipsychotic Drugs. Neuroscience 361, 43-57. doi:10.1016/j.neuroscience.2017.07.068

Lee, H.-J., and Kang, S.-G. (2011). "Genetics of Tardive Dyskinesia," in International Review of Neurobiology, 231-264. doi:10.1016/b978-0-12381328-2.00010-9

Lemke, J. R., Lal, D., Reinthaler, E. M., Steiner, I., Nothnagel, M., Alber, M., et al. (2013). Mutations in GRIN2A Cause Idiopathic Focal Epilepsy with Rolandic Spikes. Nat. Genet. 45, 1067-1072. doi:10.1038/ng.2728

Lerer, B., Segman, R. H., Fangerau, H., Daly, A. K., Basile, V. S., Cavallaro, R., et al. (2002). Pharmacogenetics of Tardive Dyskinesia: Combined Analysis of 780 Patients Supports Association with Dopamine D3 Receptor Gene Ser9Gly Polymorphism. Neuropsychopharmacology 27, 105-119. doi:10.1016/S0893133X(02)00293-2

Lerer, B., Segman, R. H., Tan, E. C., Basile, V. S., Cavallaro, R., Aschauer, H. N., et al. (2005). Combined Analysis of 635 Patients Confirms an Age-Related 
Association of the Serotonin 2A Receptor Gene with Tardive Dyskinesia and Specificity for the Non-orofacial Subtype. Int. J. Neuropsychopharmacol. 8, 411-425. doi:10.1017/S1461145705005389

Lesca, G., Rudolf, G., Bruneau, N., Lozovaya, N., Labalme, A., Boutry-Kryza, N., et al. (2013). GRIN2A Mutations in Acquired Epileptic Aphasia and Related Childhood Focal Epilepsies and Encephalopathies with Speech and Language Dysfunction. Nat. Genet. 45, 1061-1066. doi:10.1038/ng.2726

Levchenko, A., Vyalova, N., Pozhidaev, I. V., Boiko, A. S., Osmanova, D. Z., Fedorenko, O. Y., et al. (2019). No Evidence So Far of a Major Role of AKT1 and GSK3B in the Pathogenesis of Antipsychotic-Induced Tardive Dyskinesia. Hum. Psychopharmacol. Clin. Exp. 34, e2685. doi:10.1002/hup.2685

Li, H., Tan, Y., Wang, Z., Yang, F., Zuo, L., and Luo, X. (2013). Association Study on Tardive Dyskinesia and Polymorphisms in COMT and MAOA in Chinese Population. Psychiatr. Genet. 23, 176. doi:10.1097/YPG.0b013e32835e8df6

Liao, D. L., Yeh, Y. C., Chen, H. M., Chen, H., Hong, C. J., and Tsai, S. J. (2001). Association between the Ser9Gly Polymorphism of the Dopamine D3 Receptor Gene and Tardive Dyskinesia in Chinese Schizophrenic Patients. Neuropsychobiology 44, 95-98. doi:10.1159/000054924

Lim, K., Lam, M., Zai, C., Tay, J., Karlsson, N., Deshpande, S. N., et al. (2021). Genome Wide Study of Tardive Dyskinesia in Schizophrenia. Transl Psychiatry 11, 351. doi:10.1038/s41398-021-01471-y

Liou, Y. J., Wang, Y. C., Bai, Y. M., Lin, C. C., Yu, S. C., Liao, D. L., et al. (2004). Cytochrome P-450 2D6*10 C188T Polymorphism Is Associated with Antipsychotic-Induced Persistent Tardive Dyskinesia in Chinese Schizophrenic Patients. Neuropsychobiology 49, 167-173. doi:10.1159/ 000077360

Liou, Y. J., Lai, I. C., Liao, D. L., Chen, J. Y., Lin, C. C., Lin, C. Y., et al. (2006). The Human Dopamine Receptor D2 (DRD2) Gene Is Associated with Tardive Dyskinesia in Patients with Schizophrenia. Schizophr Res. 86, 323-325. doi:10.1016/j.schres.2006.04.008

Løvlie, R., Daly, A. K., Blennerhassett, R., Ferrier, N., and Steen, V. M. (2000). Homozygosity for the Gly-9 Variant of the Dopamine D3 Receptor and Risk for Tardive Dyskinesia in Schizophrenic Patients. Int. J. Neuropsychopharm. 3, 61-65. doi:10.1017/S1461145700001796

Lohmann, P. L., Bagli, M., Krauss, H., Müller, D. J., Schulze, T. G., Fangerau, H., et al. (2003). CYP2D6 Polymorphism and Tardive Dyskinesia in Schizophrenic Patients. Pharmacopsychiatry 36, 73-78. doi:10.1055/s-2003-39048

Lott, D. C., Kim, S. J., Cook, E. H., and de Wit, H. (2005). Dopamine Transporter Gene Associated with Diminished Subjective Response to Amphetamine. Neuropsychopharmacology 30, 602-609. doi:10.1038/sj.npp.1300637

Loughlin, A. M., Lin, N., Abler, V., and Carroll, B. (2019). Tardive Dyskinesia Among Patients Using Antipsychotic Medications in Customary Clinical Care in the United States. PLoS One 14, e0216044. doi:10.1371/ journal.pone. 0216044

Lu, J. Y., Tiwari, A. K., Zai, G. C., Rastogi, A., Shaikh, S. A., Müller, D. J., et al. (2018). Association Study of Disrupted-In-Schizophrenia-1 Gene Variants and Tardive Dyskinesia. Neurosci. Lett. 686, 17-22. doi:10.1016/j.neulet.2018.08.007

Lu, J. Y., Tiwari, A. K., Freeman, N., Zai, G. C., Luca, V., Müller, D. J., et al. (2020). Liver Enzyme CYP2D6 Gene and Tardive Dyskinesia. Pharmacogenomics 21, 1065-1072. doi:10.2217/pgs-2020-0065

Luo, X., Kranzler, H. R., Zuo, L., Wang, S., Blumberg, H. P., and Gelernter, J. (2005). CHRM2 Gene Predisposes to Alcohol Dependence, Drug Dependence and Affective Disorders: Results from an Extended CaseControl Structured Association Study. Hum. Mol. Genet. 14, 2421-2434. doi: $10.1093 / \mathrm{hmg} / \mathrm{ddi} 244$

Lv, Z., Rong, B., Tong, X., Li, X., Chen, X., Wang, X., et al. (2016). The Association between COMT Val158Met Gene Polymorphism and Antipsychotic-Induced Tardive Dyskinesia Risk. Int. J. Neurosci. 126, 1044-1050. doi:10.3109/ 00207454.2015.1089504

Maes, M. S., Lu, J. Y., Tiwari, A. K., Freeman, N., de Luca, V., Müller, D. J., et al. (2021). Schizophrenia-associated Gene Dysbindin-1 and Tardive Dyskinesia. Drug Dev. Res. 82, 678-684. doi:10.1002/ddr.21681

Mahmoudi, S., Blanchet, P. J., and Lévesque, D. (2013). Haloperidol-induced Striatal Nur77 Expression in a Non-human Primate Model of Tardive Dyskinesia. Eur. J. Neurosci. 38, 2192-2198. doi:10.1111/ejn.12198

Mahmoudi, S., Lévesque, D., and Blanchet, P. J. (2014). Upregulation of Dopamine D3, Not D2, Receptors Correlates with Tardive Dyskinesia in a Primate Model. Mov Disord. 29, 1125-1133. doi:10.1002/mds.25909
Marder, S. R., and Cannon, T. D. (2019). Schizophrenia. N. Engl. J. Med. 381, 1753-1761. doi:10.1056/NEJMra1808803

Matar, H. E., Almerie, M. Q., and Sampson, S. J. (2018). Fluphenazine (Oral) versus Placebo for Schizophrenia. Cochrane Database Syst. Rev. 6, CD006352. doi:10.1002/14651858.CD006352.pub3

Matsumoto, C., Ohmori, O., Shinkai, T., Hori, H., and Nakamura, J. (2004a). Genetic Association Analysis of Functional Polymorphisms in the Cytochrome P450 1A2 (CYP1A2) Gene with Tardive Dyskinesia in Japanese Patients with Schizophrenia. Psychiatr. Genet. 14, 209-213. doi:10.1097/00041444200412000-00008

Matsumoto, C., Shinkai, T., Hori, H., Ohmori, O., and Nakamura, J. (2004b). Polymorphisms of Dopamine Degradation Enzyme (COMT and MAO) Genes and Tardive Dyskinesia in Patients with Schizophrenia. Psychiatry Res. 127, 1-7. doi:10.1016/j.psychres.2004.03.011

McMahon, F. J., Buervenich, S., Charney, D., Lipsky, R., Rush, A. J., Wilson, A. F., et al. (2006). Variation in the Gene Encoding the Serotonin 2A Receptor Is Associated with Outcome of Antidepressant Treatment. Am. J. Hum. Genet. 78, 804-814. doi:10.1086/503820

Mechaussier, S., Almoallem, B., Zeitz, C., Van Schil, K., Jeddawi, L., Van Dorpe, J., et al. (2020). Loss of Function of RIMS2 Causes a Syndromic Congenital ConeRod Synaptic Disease with Neurodevelopmental and Pancreatic Involvement. Am. J. Hum. Genet. 107, 580-871. doi:10.1016/j.ajhg.2020.04.01810.1016/ j.ajhg.2020.08.004

Mentzel, C. L., Bakker, P. R., van Os, J., Drukker, M., Matroos, G. E., Hoek, H. W., et al. (2017). Effect of Antipsychotic Type and Dose Changes on Tardive Dyskinesia and Parkinsonism Severity in Patients with a Serious Mental Illness: The Curaçao Extrapyramidal Syndromes Study XII. J. Clin. Psychiatry 78, e279-e285. doi:10.4088/JCP.16m11049

Miksys, S., Wadji, F. B., Tolledo, E. C., Remington, G., Nobrega, J. N., and Tyndale, R. F. (2017). Rat Brain CYP2D Enzymatic Metabolism Alters Acute and Chronic Haloperidol Side-Effects by Different Mechanisms. Prog. Neuropsychopharmacol. Biol. Psychiatry 78, 140-148. doi:10.1016/ j.pnpbp.2017.04.030

Miller, D. D., Caroff, S. N., Davis, S. M., Rosenheck, R. A., McEvoy, J. P., Saltz, B. L., et al. (2008). Extrapyramidal Side-Effects of Antipsychotics in a Randomised Trial. Br. J. Psychiatry 193, 279-288. doi:10.1192/bjp.bp.108.050088

Mizuta, S., Minami, T., Fujita, H., Kaminaga, C., Matsui, K., Ishino, R., et al. (2014). CCAR1/CoCoA Pair-Mediated Recruitment of the Mediator Defines a Novel Pathway for GATA1 Function. Genes Cells 19, 28-51. doi:10.1111/gtc.12104

Mobascher, A., Rujescu, D., Mittelstraß, K., Giegling, I., Lamina, C., Nitz, B., et al. (2010). Association of a Variant in the Muscarinic Acetylcholine Receptor 2 Gene (CHRM2) with Nicotine Addiction. Am. J. Med. Genet. B Neuropsychiatr. Genet. 153B, 684-690. doi:10.1002/ajmg.b.31011

Müller, D. J., Chiesa, A., Mandelli, L., Luca, V. D., Ronchi, D. D., Jain, U., et al. (2010). Correlation of a Set of Gene Variants, Life Events and Personality Features on Adult ADHD Severity. J. Psychiatr. Res. 44, 598-604. doi:10.1016/ j.jpsychires.2009.11.011

Nade, V. S., Shendye, N. V., Kawale, L. A., Patil, N. R., and Khatri, M. L. (2013). Protective Effect of Nebivolol on Reserpine-Induced Neurobehavioral and Biochemical Alterations in Rats. Neurochem. Int. 63, 316-321. doi:10.1016/ j.neuint.2013.07.002

Nagaoka, K., Nagashima, T., Asaoka, N., Yamamoto, H., Toda, C., Kayanuma, G., et al. (2021). Striatal TRPV1 Activation by Acetaminophen Ameliorates Dopamine D2 Receptor Antagonist-Induced Orofacial Dyskinesia. JCI Insight 6, e145632. doi:10.1172/jci.insight.145632

Nguyen, T. V., Janssen, M. J., van Oijen, M. G., Bergevoet, S. M., te Morsche, R. H., van Asten, H., et al. (2010). Genetic Polymorphisms in GSTA1, GSTP1, GSTT1, and GSTM1 and Gastric Cancer Risk in a Vietnamese Population. Oncol. Res. 18, 349-355. doi:10.3727/096504010x12626118080064

Nikoloff, D., Shim, J. C., Fairchild, M., Patten, N., Fijal, B. A., Koch, W. H., et al. (2002). Association between CYP2D6 Genotype and Tardive Dyskinesia in Korean Schizophrenics. Pharmacogenomics J. 2, 400-407. doi:10.1038/ sj.tpj. 6500138

Nthiga, T. M., Kumar Shrestha, B., Sjøttem, E., Bruun, J. A., Bowitz Larsen, K., Bhujabal, Z., et al. (2020). CALCOCO1 Acts with VAMP-Associated Proteins to Mediate ER-Phagy. EMBO J. 39, e103649. doi:10.15252/embj.2019103649

Nunokawa, A., Watanabe, Y., Kaneko, N., Sugai, T., Yazaki, S., Arinami, T., et al. (2010). The Dopamine D3 Receptor (DRD3) Gene and Risk of Schizophrenia: 
Case-Control Studies and an Updated Meta-Analysis. Schizophr Res. 116, 61-67. doi:10.1016/j.schres.2009.10.016

Oddi, S., Dainese, E., Sandiford, S., Fezza, F., Lanuti, M., Chiurchiù, V., et al. (2012). Effects of Palmitoylation of Cys(415) in helix 8 of the $\mathrm{CB}(1)$ Cannabinoid Receptor on Membrane Localization and Signalling. Br. J. Pharmacol. 165, 2635-2651. doi:10.1111/j.1476-5381.2011.01658.x

Ohmori, O., Suzuki, T., Kojima, H., Shinkai, T., Terao, T., Mita, T., et al. (1998). Tardive Dyskinesia and Debrisoquine 4-hydroxylase (CYP2D6) Genotype in Japanese Schizophrenics. Schizophr Res. 32, 107-113. doi:10.1016/s09209964(98)00018-8

Ohmori, O., Kojima, H., Shinkai, T., Terao, T., Suzuki, T., and Abe, K. (1999). Genetic Association Analysis between CYP2D6*2 Allele and Tardive Dyskinesia in Schizophrenic Patients. Psychiatry Res. 87, 239-244. doi:10.1016/s0165-1781(99)00065-7

Ohmori, O., Shinkai, T., Hori, H., Kojima, H., and Nakamura, J. (2001). Polymorphisms of $\mathrm{Mu}$ and delta Opioid Receptor Genes and Tardive Dyskinesia in Patients with Schizophrenia. Schizophr Res. 52, 137-138. doi:10.1016/s0920-9964(00)00188-2

Ohmori, O., Shinkai, T., Hori, H., and Nakamura, J. (2002). Genetic Association Analysis of 5-HT(6) Receptor Gene Polymorphism (267C/ T) with Tardive Dyskinesia. Psychiatry Res. 110, 97-102. doi:10.1016/ s0165-1781(02)00095-1

Ohmori, O., Shinkai, T., Hori, H., Matsumoto, C., and Nakamura, J. (2003). A Perspective on Molecular Genetic Studies of Tardive Dyskinesia: One Clue for Individualized Antipsychotic Drug Therapy. Prog. Neuropsychopharmacol. Biol. Psychiatry 27, 581-586. doi:10.1016/S0278-5846(03)00082-4

Owens, D. C. (2019). Tardive Dyskinesia Update: the Syndrome. BJPsych Adv. 25, 57-69. doi:10.1192/bja.2018.45

Park, Y. M., Kang, S. G., Choi, J. E., Kim, Y. K., Kim, S. H., Park, J. Y., et al. (2011). No Evidence for an Association between Dopamine D2 Receptor Polymorphisms and Tardive Dyskinesia in Korean Schizophrenia Patients. Psychiatry Investig. 8, 49-54. doi:10.4306/pi.2011.8.1.49

Patil, R. A., Hiray, Y. A., and Kasture, S. B. (2012). Reversal of Reserpine-Induced Orofacial Dyskinesia and Catalepsy by Nardostachys Jatamansi. Indian J. Pharmacol. 44, 340-344. doi:10.4103/0253-7613.96307

Patsopoulos, N. A., Ntzani, E. E., Zintzaras, E., and Ioannidis, J. P. (2005). CYP2D6 Polymorphisms and the Risk of Tardive Dyskinesia in Schizophrenia: a MetaAnalysis. Pharmacogenet Genomics 15, 151-158. doi:10.1097/01213011200503000-00003

Patterson-Lomba, O., Ayyagari, R., and Carroll, B. (2019). Risk Assessment and Prediction of TD Incidence in Psychiatric Patients Taking Concomitant Antipsychotics: a Retrospective Data Analysis. BMC Neurol. 19, 174. doi:10.1186/s12883-019-1385-4

Peluso, M. J., Lewis, S. W., Barnes, T. R., and Jones, P. B. (2012). Extrapyramidal Motor Side-Effects of First- and Second-Generation Antipsychotic Drugs. Br. J. Psychiatry 200, 387-392. doi:10.1192/bjp.bp.111.101485

Peroza, L. R., Schaffer, L. F., De Freitas, C. M., Leal, C. Q., Ferrari, M. C., Duarte, M. M., et al. (2016). Alteration of Cytokines Levels in the Striatum of Rats: Possible Participation in Vacuous Chewing Movements Induced by Antipsycotics. Neurochem. Res. 41, 2481-2489. doi:10.1007/s11064-016-1961-6

Petrović, J., Pešić, V., and Lauschke, V. M. (2020). Frequencies of Clinically Important CYP2C19 and CYP2D6 Alleles Are Graded across Europe. Eur. J. Hum. Genet. 28, 88-94. doi:10.1038/s41431-019-0480-8

Piacentini, S., Polimanti, R., Moscatelli, B., Re, M. A., Fuciarelli, R., Manfellotto, D., et al. (2010). Glutathione S-Transferase Gene Polymorphisms and Air Pollution as Interactive Risk Factors for Asthma in a Multicentre Italian Field Study: A Preliminary Study. Ann. Hum. Biol. 37, 427-439. doi:10.3109/ 03014461003636419

Plesnicar, B. K., Zalar, B., Breskvar, K., and Dolzan, V. (2006). The Influence of the CYP2D6 Polymorphism on Psychopathological and Extrapyramidal Symptoms in the Patients on Long-Term Antipsychotic Treatment. J. Psychopharmacol. 20, 829-833. doi:10.1177/0269881106062894

Pozhidaev, I. V., Paderina, D. Z., Fedorenko, O. Y., Kornetova, E. G., Semke, A. V., Loonen, A. J. M., et al. (2020). 5-Hydroxytryptamine Receptors and Tardive Dyskinesia in Schizophrenia. Front. Mol. Neurosci. 13, 63. doi:10.3389/ fnmol.2020.00063

Proudnikov, D., Kroslak, T., Sipe, J. C., Randesi, M., Li, D., Hamon, S., et al. (2010). Association of Polymorphisms of the Cannabinoid Receptor (CNR1) and Fatty
Acid Amide Hydrolase (FAAH) Genes with Heroin Addiction: Impact of Long Repeats of CNR1. Pharmacogenomics J. 10, 232-242. doi:10.1038/tpj.2009.59

Rameh, L. E., Tolias, K. F., Duckworth, B. C., and Cantley, L. C. (1997). A New Pathway for Synthesis of Phosphatidylinositol-4,5-Bisphosphate. Nature 390, 192-196. doi:10.1038/36621

Ravyn, D., Ravyn, V., Lowney, R., and Nasrallah, H. A. (2013). CYP450 Pharmacogenetic Treatment Strategies for Antipsychotics: a Review of the Evidence. Schizophr Res. 149, 1-14. doi:10.1016/j.schres.2013.06.035

Reinheimer, J. B., Bressan, G. N., de Freitas, C. M., Ceretta, A. P. C., Krum, B. N., Nogara, P. A., et al. (2020). Effects of CATECHIN on Reserpine-Induced Vacuous Chewing Movements: Behavioral and Biochemical Analysis. Naunyn Schmiedebergs Arch. Pharmacol. 393, 2439-2452. doi:10.1007/s00210-02001923-0

Relling, M. V., and Klein, T. E. (2011). CPIC: Clinical Pharmacogenetics Implementation Consortium of the Pharmacogenomics Research Network. Clin. Pharmacol. Ther. 89, 464-467. doi:10.1038/clpt.2010.279

Reynolds, G. P. (2007). The Impact of Pharmacogenetics on the Development and Use of Antipsychotic Drugs. Drug Discov. Today 12, 953-959. doi:10.1016/ j.drudis.2007.07.018

Ricciardi, L., Pringsheim, T., Barnes, T. R. E., Martino, D., Gardner, D., Remington, G., et al. (2019). Treatment Recommendations for Tardive Dyskinesia. Can. J. Psychiatry 64, 388-399. doi:10.1177/0706743719828968

Rietschel, M., Krauss, H., Müller, D. J., Schulze, T. G., Knapp, M., Marwinski, K., et al. (2000). Dopamine D3 Receptor Variant and Tardive Dyskinesia. Eur. Arch. Psychiatry Clin. Neurosci. 250, 31-35. doi:10.1007/pl00007536

Rilstone, J. J., Alkhater, R. A., and Minassian, B. A. (2013). Brain DopamineSerotonin Vesicular Transport Disease and its Treatment. N. Engl. J. Med. 368, 543-550. doi:10.1056/NEJMoa1207281

Röpke, J., Ferreira-Vieira, T. H., Iglesias, L. P., Asth, L., Ribeiro, F. M., and Moreira, F. A. (2021). Protective Role of Endocannabinoid Signaling in an Animal Model of Haloperidol-Induced Tardive Dyskinesia. Pharmacol. Biochem. Behav. 206, 173193. doi:10.1016/j.pbb.2021.173193

Rybakowski, J. K., Dmitrzak-Weglarz, M., Suwalska, A., Leszczynska-Rodziewicz, A., and Hauser, J. (2009). Dopamine D1 Receptor Gene Polymorphism Is Associated with Prophylactic Lithium Response in Bipolar Disorder. Pharmacopsychiatry 42, 20-22. doi:10.1055/s-0028-1085441

Sáiz, P. A., García-Portilla, M. P., Arango, C., Morales, B., Arias, B., Corcoran, P., et al. (2010). Genetic Polymorphisms in the Dopamine-2 Receptor (DRD2), Dopamine-3 Receptor (DRD3), and Dopamine Transporter (SLC6A3) Genes in Schizophrenia: Data from an Association Study. Prog. NeuroPsychopharmacol. Biol. Psychiatry 34, 26-31. doi:10.1016/j.pnpbp.2009.09.008

Saitoh, Y., Ohno, N., Yamauchi, J., Sakamoto, T., and Terada, N. (2017). Deficiency of a Membrane Skeletal Protein, 4.1G, Results in Myelin Abnormalities in the Peripheral Nervous System. Histochem. Cel Biol 148, 597-606. doi:10.1007/ s00418-017-1600-6

Sakoda, L. C., Blackston, C. R., Xue, K., Doherty, J. A., Ray, R. M., Lin, M. G., et al. (2008). Glutathione S-Transferase M1 and P1 Polymorphisms and Risk of Breast Cancer and Fibrocystic Breast Conditions in Chinese Women. Breast Cancer Res. Treat. 109, 143-155. doi:10.1007/s10549-007-9633-5

Samad, N., and Haleem, D. J. (2017). Antioxidant Effects of rice Bran Oil Mitigate Repeated Haloperidol-Induced Tardive Dyskinesia in Male Rats. Metab. Brain Dis. 32, 1099-1107. doi:10.1007/s11011-017-0002-8

Schaffer, L. F., de Freitas, C. M., Chiapinotto Ceretta, A. P., Peroza, L. R., de Moraes Reis, E., Krum, B. N., et al. (2016). Harpagophytum Procumbens Ethyl Acetate Fraction Reduces Fluphenazine-Induced Vacuous Chewing Movements and Oxidative Stress in Rat Brain. Neurochem. Res. 41, 1170-1184. doi:10.1007/ s11064-015-1811-y

Schooler, N. R., and Kane, J. M. (1982). Research Diagnoses for Tardive Dyskinesia. Arch. Gen. Psychiatry 39, 486-487. doi:10.1001/archpsyc.1982.04290040080014

Schulze, T. G., Schumacher, J., Müller, D. J., Krauss, H., Alfter, D., Maroldt, A., et al. (2001). Lack of Association between a Functional Polymorphism of the Cytochrome P450 1A2 (CYP1A2) Gene and Tardive Dyskinesia in Schizophrenia. Am. J. Med. Genet. 105, 498-501. doi:10.1002/ajmg.1472

Schwab, S. G., Franke, P. E., Hoefgen, B., Guttenthaler, V., Lichtermann, D., Trixler, M., et al. (2005). Association of DNA Polymorphisms in the Synaptic Vesicular Amine Transporter Gene (SLC18A2) with Alcohol and Nicotine Dependence. Neuropsychopharmacology 30, 2263-2268. doi:10.1038/ sj.npp.1300809 
Schwartzbaum, J. A., Ahlbom, A., Lönn, S., Warholm, M., Rannug, A., Auvinen, A., et al. (2007). An International Case-Control Study of Glutathione Transferase and Functionally Related Polymorphisms and Risk of Primary Adult Brain Tumors. Cancer Epidemiol. Biomarkers Prev. 16, 559-565. doi:10.1158/10559965.EPI-06-0918

Scordo, M. G., Spina, E., Romeo, P., Dahl, M. L., Bertilsson, L., Johansson, I., et al. (2000). CYP2D6 Genotype and Antipsychotic-Induced Extrapyramidal Side Effects in Schizophrenic Patients. Eur. J. Clin. Pharmacol. 56, 679-683. doi:10.1007/s002280000222

Segman, R., Neeman, T., Heresco-Levy, U., Finkel, B., Karagichev, L., Schlafman, M., et al. (1999). Genotypic Association between the Dopamine D3 Receptor and Tardive Dyskinesia in Chronic Schizophrenia. Mol. Psychiatry 4, 247-253. doi:10.1038/sj.mp.4000511

Segman, R. H., Heresco-Levy, U., Finkel, B., Inbar, R., Neeman, T., Schlafman, M., et al. (2000). Association between the Serotonin 2C Receptor Gene and Tardive Dyskinesia in Chronic Schizophrenia: Additive Contribution of 5-HT2Cser and DRD3gly Alleles to Susceptibility. Psychopharmacology (Berl) 152, 408-413. doi: $10.1007 / \mathrm{s} 002130000521$

Segman, R. H., Heresco-Levy, U., Finkel, B., Goltser, T., Shalem, R., Schlafman, M., et al. (2001). Association between the Serotonin 2A Receptor Gene and Tardive Dyskinesia in Chronic Schizophrenia. Mol. Psychiatry 6, 225-229. doi:10.1038/ sj.mp. 4000842

Segman, R. H., Heresco-Levy, U., Yakir, A., Goltser, T., Strous, R., Greenberg, D. A., et al. (2002a). Interactive Effect of Cytochrome P450 17alpha-Hydroxylase and Dopamine D3 Receptor Gene Polymorphisms on Abnormal Involuntary Movements in Chronic Schizophrenia. Biol. Psychiatry 51, 261-263. doi:10.1016/s0006-3223(01)01302-6

Segman, R. H., Shapira, Y., Modai, I., Hamdan, A., Zislin, J., Heresco-Levy, U., et al. (2002b). Angiotensin Converting Enzyme Gene Insertion/deletion Polymorphism: Case-Control Association Studies in Schizophrenia, Major Affective Disorder, and Tardive Dyskinesia and a Family-Based Association Study in Schizophrenia. Am. J. Med. Genet. 114, 310-314. doi:10.1002/ ajmg. 10255

Segman, R. H., Goltser, T., Heresco-Levy, U., Finkel, B., Shalem, R., Schlafman, M., et al. (2003). Association of Dopaminergic and Serotonergic Genes with Tardive Dyskinesia in Patients with Chronic Schizophrenia. Pharmacogenomics J. 3, 277-283. doi:10.1038/sj.tpj.6500194

Sekiguchi, K., Kanno, H., Yamaguchi, T., Ikarashi, Y., and Kase, Y. (2012). Ameliorative Effect of Yokukansan on Vacuous Chewing Movement in Haloperidol-Induced Rat Tardive Dyskinesia Model and Involvement of Glutamatergic System. Brain Res. Bull. 89, 151-158. doi:10.1016/ j.brainresbull.2012.08.008

Šerý, O., Přikryl, R., Častulík, L., and Štastný, F. (2010). A118G Polymorphism of OPRM1 Gene Is Associated with Schizophrenia. J. Mol. Neurosci. 41, 219-222. doi:10.1007/s12031-010-9327-z

Shi, J., Tan, Y. L., Wang, Z. R., An, H. M., Li, J., Wang, Y. C., et al. (2016). Ginkgo Biloba and Vitamin E Ameliorate Haloperidol-Induced Vacuous Chewingmovement and Brain-Derived Neurotrophic Factor Expression in a Rat Tardive Dyskinesia Model. Pharmacol. Biochem. Behav. 148, 53-58. doi:10.1016/j.pbb.2016.06.003

Shinkai, T., Ohmori, O., Matsumoto, C., Hori, H., Kennedy, J. L., and Nakamura, J. (2004). Genetic Association Analysis of Neuronal Nitric Oxide Synthase Gene Polymorphism with Tardive Dyskinesia. Neuromolecular Med. 5, 163-170. doi:10.1385/NMM:5:2:163

Shinkai, T., De Luca, V., Hwang, R., Matsumoto, C., Hori, H., Ohmori, O., et al. (2005). Association Study between a Functional Glutathione S-Transferase (GSTP1) Gene Polymorphism (Ile105Val) and Tardive Dyskinesia. Neurosci. Lett. 388, 116-120. doi:10.1016/j.neulet.2005.06.038

Shinkai, T., Müller, D. J., De Luca, V., Shaikh, S., Matsumoto, C., Hwang, R., et al. (2006). Genetic Association Analysis of the Glutathione Peroxidase (GPX1) Gene Polymorphism (Pro197Leu) with Tardive Dyskinesia. Psychiatry Res. 141, 123-128. doi:10.1016/j.psychres.2004.06.023

Sivakumaren, S. C., Shim, H., Zhang, T., Ferguson, F. M., Lundquist, M. R., Browne, C. M., et al. (2020). Targeting the PI5P4K Lipid Kinase Family in Cancer Using Covalent Inhibitors. Cell Chem Biol 27, 525-537.e6. doi:10.1016/ j.chembiol.2020.02.003

So, H. C., Fong, P. Y., Chen, R. Y., Hui, T. C., Ng, M. Y., Cherny, S. S., et al. (2010). Identification of Neuroglycan $\mathrm{C}$ and Interacting Partners as Potential
Susceptibility Genes for Schizophrenia in a Southern Chinese Population. Am. J. Med. Genet. B Neuropsychiatr. Genet. 153B, 103-113. doi:10.1002/ ajmg.b.30961

Son, W. Y., Lee, H. J., Yoon, H. K., Kang, S. G., Park, Y. M., Yang, H. J., et al. (2014). Gaba Transporter SLC6A11 Gene Polymorphism Associated with Tardive Dyskinesia. Nord J. Psychiatry 68, 123-128. doi:10.3109/08039488.2013.780260

Sonego, A. B., Prado, D. S., Vale, G. T., Sepulveda-Diaz, J. E., Cunha, T. M., Tirapelli, C. R., et al. (2018). Cannabidiol Prevents Haloperidol-Induced Vacuos Chewing Movements and Inflammatory Changes in Mice via PPAR $\gamma$ Receptors. Brain Behav. Immun. 74, 241-251. doi:10.1016/j.bbi.2018.09.014

Soung, H. S., Wang, M. H., Chang, K. C., Chen, C. N., Chang, Y., Yang, C. C., et al. (2018). L-theanine Decreases Orofacial Dyskinesia Induced by Reserpine in Rats. Neurotox Res. 34, 375-387. doi:10.1007/s12640-018-9897-z

Srivastava, V., Varma, P. G., Prasad, S., Semwal, P., Nimgaonkar, V. L., Lerer, B., et al. (2006). Genetic Susceptibility to Tardive Dyskinesia Among Schizophrenia Subjects: IV. Role of Dopaminergic Pathway Gene Polymorphisms. Pharmacogenet Genomics 16, 111-117. doi:10.1097/ 01.fpc.0000184957.98150.0f

Stauch, B., Johansson, L. C., McCorvy, J. D., Patel, N., Han, G. W., Huang, X. P., et al. (2019). Structural Basis of Ligand Recognition at the Human MT1 Melatonin Receptor. Nature 569, 284-288. doi:10.1038/s41586-019-1141-3

Steen, V. M., Løvlie, R., MacEwan, T., and McCreadie, R. G. (1997). Dopamine D3Receptor Gene Variant and Susceptibility to Tardive Dyskinesia in Schizophrenic Patients. Mol. Psychiatry 2, 139-145. doi:10.1038/sj.mp.4000249

Strohmaier, J., Frank, J., Wendland, J. R., Schumacher, J., Jamra, R. A., Treutlein, J., et al. (2010). A Reappraisal of the Association between Dysbindin (DTNBP1) and Schizophrenia in a Large Combined Case-Control and Family-Based Sample of German Ancestry. Schizophr Res. 118, 98-105. doi:10.1016/ j.schres.2009.12.025

Su, C. C., Chia-Cheng Lai, E., Kao Yang, Y. H., Man, K. K. C., Kubota, K., Stang, P., et al. (2020). Incidence, Prevalence and Prescription Patterns of Antipsychotic Medications Use in Asia and US: A Cross-Nation Comparison with Common Data Model. J. Psychiatr. Res. 131, 77-84. doi:10.1016/j.jpsychires.2020.08.025

Sun, H., Wang, F., Fan, H., Yan, Q., Cui, K., Yuan, W., et al. (2013). The Interaction of Polymorphisms of IL10 and DBH Was Associated with General Symptoms of PANSS with TD in Chinese Han Schizophrenic Patients. PLoS One 8, e70963. doi:10.1371/journal.pone. 0070963

Syu, A., Ishiguro, H., Inada, T., Horiuchi, Y., Tanaka, S., Ishikawa, M., et al. (2010). Association of the HSPG2 Gene with Neuroleptic-Induced Tardive Dyskinesia. Neuropsychopharmacology 35, 1155-1164. doi:10.1038/npp.2009.220

Takahashi, Y., Fukuda, Y., Yoshimura, J., Toyoda, A., Kurppa, K., Moritoyo, H., et al. (2013). ERBB4 Mutations that Disrupt the Neuregulin-ErbB4 Pathway Cause Amyotrophic Lateral Sclerosis Type 19. Am. J. Hum. Genet. 93, 900-905. doi:10.1016/j.ajhg.2013.09.008

Takeuchi, H., MacKenzie, N. E., Samaroo, D., Agid, O., Remington, G., and Leucht, S. (2020). Antipsychotic Dose in Acute Schizophrenia: A Meta-Analysis. Schizophr Bull. 46, 1439-1458. doi:10.1093/schbul/sbaa063

Tamminga, C., Thaker, G., Moran, M., Kakigi, T., and Gao, X. M. (1994). Clozapine in Tardive Dyskinesia: Observations from Human and Animal Model Studies. J. Clin. Psychiatry 55 Suppl B, 102-106.

Tan, E. C., Chong, S. A., Mahendran, R., Dong, F., and Tan, C. H. (2001). Susceptibility to Neuroleptic-Induced Tardive Dyskinesia and the T102C Polymorphism in the Serotonin Type 2A Receptor. Biol. Psychiatry 50, 144-147. doi:10.1016/s0006-3223(01)01076-9

Tanaka, S., Syu, A., Ishiguro, H., Inada, T., Horiuchi, Y., Ishikawa, M., et al. (2013). DPP6 as a Candidate Gene for Neuroleptic-Induced Tardive Dyskinesia. Pharmacogenomics J. 13, 27-34. doi:10.1038/tpj.2011.36

Tansey, K. E., Guipponi, M., Perroud, N., Bondolfi, G., Domenici, E., Evans, D., et al. (2012). Genetic Predictors of Response to Serotonergic and Noradrenergic Antidepressants in Major Depressive Disorder: a Genome-wide Analysis of Individual-Level Data and a Meta-Analysis. Plos Med. 9, e1001326. doi:10.1371/ journal.pmed.1001326

Thakur, K. S., Prakash, A., Bisht, R., and Bansal, P. K. (2015). Beneficial Effect of Candesartan and Lisinopril against Haloperidol-Induced Tardive Dyskinesia in Rat. J. Renin Angiotensin Aldosterone Syst. 16, 917-929. doi:10.1177/ 1470320313515038

Thiselton, D. L., Maher, B. S., Webb, B. T., Bigdeli, T. B., O'Neill, F. A., Walsh, D., et al. (2010). Association Analysis of the PIP4K2A Gene on Chromosome 
10p12 and Schizophrenia in the Irish Study of High Density Schizophrenia Families (ISHDSF) and the Irish Case-Control Study of Schizophrenia (ICCSS). Am. J. Med. Genet. B Neuropsychiatr. Genet. 153B, 323-331. doi:10.1002/ ajmg.b.30982

Tiwari, A. K., Deshpande, S. N., Rao, A. R., Bhatia, T., Mukit, S. R., Shriharsh, V., et al. (2005a). Genetic Susceptibility to Tardive Dyskinesia in Chronic Schizophrenia Subjects: I. Association of CYP1A2 Gene Polymorphism. Pharmacogenomics J. 5, 60-69. doi:10.1038/sj.tpj.6500282

Tiwari, A. K., Deshpande, S. N., Rao, A. R., Bhatia, T., Lerer, B., Nimgaonkar, V. L., et al. (2005b). Genetic Susceptibility to Tardive Dyskinesia in Chronic Schizophrenia Subjects: III. Lack of Association of CYP3A4 and CYP2D6 Gene Polymorphisms. Schizophr Res. 75, 21-26. doi:10.1016/ j.schres.2004.12.011

Tiwari, A. K., Zai, C. C., Likhodi, O., Lisker, A., Singh, D., Souza, R. P., et al. (2010). A Common Polymorphism in the Cannabinoid Receptor 1 (CNR1) Gene Is Associated with Antipsychotic-Induced Weight Gain in Schizophrenia. Neuropsychopharmacology 35, 1315-1324. doi:10.1038/npp.2009.235

Tiwari, A. K., Zai, C. C., Likhodi, O., Voineskos, A. N., Meltzer, H. Y., Lieberman, J. A., et al. (2012). Association Study of Cannabinoid Receptor 1 (CNR1) Gene in Tardive Dyskinesia. Pharmacogenomics J. 12, 260-266. doi:10.1038/ tpj.2010.93

Tolosa, E. J., Fernandez-Barrena, M. G., Iguchi, E., McCleary-Wheeler, A. L., Carr, R. M., Almada, L. L., et al. (2020). GLI1/GLI2 Functional Interplay Is Required to Control Hedgehog/GLI Targets Gene Expression. Biochem. J. 477, 3131-3145. doi:10.1042/BCJ20200335

Tsai, H. T., North, K. E., West, S. L., and Poole, C. (2010). The DRD3 Rs6280 Polymorphism and Prevalence of Tardive Dyskinesia: a Meta-Analysis. Am. J. Med. Genet. B Neuropsychiatr. Genet. 153B, 57-66. doi:10.1002/ ajmg.b.30946

Tsai, C. C., Wang, M. H., Chang, K. C., Soung, H. S., Yang, C. C., and Tseng, H. C. (2019). Possible Nitric Oxide Mechanism Involved in the Protective Effect of L-Theanine on Haloperidol-Induced Orofacial Dyskinesia. Chin. J. Physiol. 62, 17-26. doi:10.4103/CJP.CJP_8_19

Turčin, A., Dolžan, V., Porcelli, S., Serretti, A., and Plesničar, B. K. (2016). Adenosine Hypothesis of Antipsychotic Drugs Revisited: Pharmacogenomics Variation in Nonacute Schizophrenia. OMICS 20, 283-289. doi:10.1089/ omi.2016.0003

Tvorogov, D., Sundvall, M., Kurppa, K., Hollmén, M., Repo, S., Johnson, M. S., et al. (2009). Somatic Mutations of ErbB4: Selective Loss-Of-Function Phenotype Affecting Signal Transduction Pathways in Cancer. J. Biol. Chem. 284, 5582-5591. doi:10.1074/jbc.M805438200

Utsunomiya, K., Shinkai, T., Sakata, S., Yamada, K., Chen, H. I., De Luca, V., et al. (2012). Genetic Association between the Dopamine D3 Receptor Gene Polymorphism (Ser9Gly) and Tardive Dyskinesia in Patients with Schizophrenia: a Reevaluation in East Asian Populations. Neurosci. Lett. 507, 52-56. doi:10.1016/j.neulet.2011.11.050

Vasan, S., and Padhy, R. K. (2021). Tardive Dyskinesia. Arlington: StatPearls Publishing.

Vullhorst, D., Neddens, J., Karavanova, I., Tricoire, L., Petralia, R. S., McBain, C. J., et al. (2009). Selective Expression of ErbB4 in Interneurons, but Not Pyramidal Cells, of the Rodent Hippocampus. J. Neurosci. 29, 12255-12264. doi:10.1523/ JNEUROSCI.2454-09.2009

Wang, Y., Wang, J. D., Wu, H. R., Zhang, B. S., Fang, H., Ma, Q. M., et al. (2010). The Val66Met Polymorphism of the Brain-Derived Neurotrophic Factor Gene Is Not Associated with Risk for Schizophrenia and Tardive Dyskinesia in Han Chinese Population. Schizophr Res. 120, 240-242. doi:10.1016/ j.schres.2010.03.020

Wang, F., Fan, H., Sun, H., Yang, F., Luo, Y., Liu, H., et al. (2012). Association between TNF- $\alpha$ Promoter -308A/G Polymorphism and Tardive Dyskinesian Chinese Han Patients with Schizophrenia. Prog. Neuropsychopharmacol. Biol. Psychiatry 37, 106-110. doi:10.1016/j.pnpbp.2011.12.007

Wang, M.-H., Lin, R.-F., Tseng, H.-C., Soung, H.-S., Chang, K.-C., and Tsai, C.-C. (2015). (-) Epigallocatechin-3-Gallate Attenuates Reserpine-Induced Orofacial Dyskinesia and Oxidative Stress in Rat striatumEpigallocatechin-3-Gallate Attenuates Reserpine-Induced Orofacial Dyskinesia and Oxidative Stress in Rat Striatum. Pharmacol. Biochem. Behav. 131, 71-76. doi:10.1016/ j.pbb.2015.02.003
Wang, S., Che, T., Levit, A., Shoichet, B. K., Wacker, D., and Roth, B. L. (2018). Structure of the D2 Dopamine Receptor Bound to the Atypical Antipsychotic Drug Risperidone. Nature 555, 269-273. doi:10.1038/nature25758

Wang, M. H., Yang, C. C., Tseng, H. C., Fang, C. H., Lin, Y. W., and Soung, H. S. (2021a). Naringin Ameliorates Haloperidol-Induced Neurotoxicity and Orofacial Dyskinesia in a Rat Model of Human Tardive Dyskinesia. Neurotox Res. 39, 774-786. doi:10.1007/s12640-021-00333-1

Wang, W., Wang, S., Xu, A. M., Yuan, X., Huang, L., and Li, J. (2021b). Overexpression of GSE1 Related to Trastuzumab Resistance in Gastric Cancer Cells. Biomed. Res. Int. 2021, 8834923. doi:10.1155/ 2021/8834923

Whirl-Carrillo, M., McDonagh, E. M., Hebert, J. M., Gong, L., Sangkuhl, K., Thorn, C. F., et al. (2012). Pharmacogenomics Knowledge for Personalized Medicine. Clin. Pharmacol. Ther. 92, 414-417. doi:10.1038/clpt.2012.96

Whirl-Carrillo, M., Huddart, R., Gong, L., Sangkuhl, K., Thorn, C. F., Whaley, R., et al. (2021). An Evidence-Based Framework for Evaluating Pharmacogenomics Knowledge for Personalized Medicine. Clin. Pharmacol. Ther. 110, 563-572. doi:10.1002/cpt.2350

Williams, J., Spurlock, G., McGuffin, P., Mallet, J., Nöthen, M. M., Gill, M., et al. (1996). Association between Schizophrenia and T102C Polymorphism of the 5hydroxytryptamine Type 2a-Receptor Gene. European Multicentre Association Study of Schizophrenia (EMASS) Group. Lancet 347, 1294-1296. doi:10.1016/ s0140-6736(96)90939-3

Woo, S. I., Kim, J. W., Rha, E., Han, S. H., Hahn, K. H., Park, C. S., et al. (2002). Association of the Ser9Gly Polymorphism in the Dopamine D3 Receptor Gene with Tardive Dyskinesia in Korean Schizophrenics. Psychiatry Clin. Neurosci. 56, 469-474. doi:10.1046/j.1440-1819.2002.01038.x

Wu, S., Xing, Q., Gao, R., Li, X., Gu, N., Feng, G., et al. (2005). Response to Chlorpromazine Treatment May Be Associated with Polymorphisms of the DRD2 Gene in Chinese Schizophrenic Patients. Neurosci. Lett. 376, 1-4. doi:10.1016/j.neulet.2004.11.014

Yasseen, B., Kennedy, J. L., Zawertailo, L. A., and Busto, U. E. (2010). Comorbidity between Bipolar Disorder and Alcohol Use Disorder: Association of Dopamine and Serotonin Gene Polymorphisms. Psychiatry Res. 176, 30-33. doi:10.1016/ j.psychres.2008.12.009

Yoshida, K., and Takeuchi, H. (2021). Dose-dependent Effects of Antipsychotics on Efficacy and Adverse Effects in Schizophrenia. Behav. Brain Res. 402, 113098. doi:10.1016/j.bbr.2020.113098

Zai, C. C., De Luca, V., Hwang, R. W., Voineskos, A., Müller, D. J., Remington, G., et al. (2007a). Meta-analysis of Two Dopamine D2 Receptor Gene Polymorphisms with Tardive Dyskinesia in Schizophrenia Patients. Mol. Psychiatry 12, 794-795. doi:10.1038/sj.mp.4002023

Zai, C. C., Hwang, R. W., De Luca, V., Müller, D. J., King, N., Zai, G. C., et al. (2007b). Association Study of Tardive Dyskinesia and Twelve DRD2 Polymorphisms in Schizophrenia Patients. Int. J. Neuropsychopharmacol. 10, 639-651. doi:10.1017/S1461145706007152

Zai, C. C., Romano-Silva, M. A., Hwang, R., Zai, G. C., Deluca, V., Müller, D. J., et al. (2008). Genetic Study of Eight AKT1 Gene Polymorphisms and Their Interaction with DRD2 Gene Polymorphisms in Tardive Dyskinesia. Schizophr Res. 106, 248-252. doi:10.1016/j.schres.2008.08.036

Zai, C. C., Tiwari, A. K., Basile, V., De Luca, V., Müller, D. J., King, N., et al. (2009a). Association Study of Tardive Dyskinesia and Five DRD4 Polymorphisms in Schizophrenia Patients. Pharmacogenomics J. 9, 168-174. doi:10.1038/ tpj.2009.2

Zai, C. C., Tiwari, A. K., De Luca, V., Müller, D. J., Bulgin, N., Hwang, R., et al. (2009b). Genetic Study of BDNF, DRD3, and Their Interaction in Tardive Dyskinesia. Eur. Neuropsychopharmacol. 19, 317-328. doi:10.1016/ j.euroneuro.2009.01.001

Zai, C. C., Tiwari, A. K., Basile, V., de Luca, V., Müller, D. J., Voineskos, A. N., et al. (2010a). Oxidative Stress in Tardive Dyskinesia: Genetic Association Study and Meta-Analysis of NADPH Quinine Oxidoreductase 1 (NQO1) and Superoxide Dismutase 2 (SOD2, MnSOD) Genes. Prog. Neuropsychopharmacol. Biol. Psychiatry 34, 50-56. doi:10.1016/j.pnpbp.2009.09.020

Zai, C. C., Tiwari, A. K., Müller, D. J., De Luca, V., Shinkai, T., Shaikh, S., et al. (2010b). The Catechol-O-Methyl-Transferase Gene in Tardive Dyskinesia. World J. Biol. Psychiatry 11, 803-812. doi:10.3109/15622975.2010.486043 
Zai, C. C., Tiwari, A. K., Mazzoco, M., de Luca, V., Müller, D. J., Shaikh, S. A., et al. (2013). Association Study of the Vesicular Monoamine Transporter Gene SLC18A2 with Tardive Dyskinesia. J. Psychiatr. Res. 47, 1760-1765. doi:10.1016/j.jpsychires.2013.07.025

Zai, C. C., Lee, F. H., Tiwari, A. K., Lu, J. Y., de Luca, V., Maes, M. S., et al. (2018a). Investigation of the HSPG2 Gene in Tardive Dyskinesia - New Data and MetaAnalysis. Front. Pharmacol. 9, 974. doi:10.3389/fphar.2018.00974

Zai, C. C., Tiwari, A. K., Zai, G. C., Maes, M. S., and Kennedy, J. L. (2018b). New Findings in Pharmacogenetics of Schizophrenia. Curr. Opin. Psychiatry 31, 200-212. doi:10.1097/YCO.0000000000000417

Zai, C. C., Tiwari, A. K., Chowdhury, N. I., Yilmaz, Z., de Luca, V., Müller, D. J., et al. (2019a). Genetic Study of Neuregulin 1 and Receptor Tyrosine-Protein Kinase erbB-4 in Tardive Dyskinesia. World J. Biol. Psychiatry 20, 91-95. doi:10.1080/15622975.2017.1301681

Zai, C. C., Tiwari, A. K., Zai, G. C., Freeman, N., Pouget, J. G., Greco, J., et al. (2019b). Association Study of the Complement Component C4 Gene in Tardive Dyskinesia. Front. Pharmacol. 10, 1339. doi:10.3389/fphar.2019.01339

Zhang, Z. J., Zhang, X. B., Sha, W. W., Zhang, X. B., and Reynolds, G. P. (2002a). Association of a Polymorphism in the Promoter Region of the Serotonin 5HT2C Receptor Gene with Tardive Dyskinesia in Patients with Schizophrenia. Mol. Psychiatry 7, 670-671. doi:10.1038/sj.mp.4001052

Zhang, Z., Zhang, X., Hou, G., Sha, W., and Reynolds, G. P. (2002b). The Increased Activity of Plasma Manganese Superoxide Dismutase in Tardive Dyskinesia Is
Unrelated to the Ala-9Val Polymorphism. J. Psychiatr. Res. 36, 317-324. doi:10.1016/s0022-3956(02)00007-9

Zhang, X. Y., Zhang, W. F., Zhou, D. F., Chen, D. C., Xiu, M. H., Wu, H. R., et al. (2012). Brain-derived Neurotrophic Factor Levels and its Val66Met Gene Polymorphism Predict Tardive Dyskinesia Treatment Response to Ginkgo Biloba. Biol. Psychiatry 72, 700-706. doi:10.1016/ j.biopsych.2012.04.032

Zhou, N., Yu, Q., Li, X., Yu, Y., Kou, C., Li, W., et al. (2013). Association of the Dopamine $\beta$-hydroxylase $19 \mathrm{Bp}$ Insertion/deletion Polymorphism with Positive Symptoms but Not Tardive Dyskinesia in Schizophrenia. Hum. Psychopharmacol. 28, 230-237. doi:10.1002/hup.2311

Conflict of Interest: The authors declare that the research was conducted in the absence of any commercial or financial relationships that could be construed as a potential conflict of interest.

Copyright (c) 2022 Tsermpini, Redenšek and Dolžan. This is an open-access article distributed under the terms of the Creative Commons Attribution License (CC BY). The use, distribution or reproduction in other forums is permitted, provided the original author(s) and the copyright owner(s) are credited and that the original publication in this journal is cited, in accordance with accepted academic practice. No use, distribution or reproduction is permitted which does not comply with these terms. 